\title{
DETERMINAÇÃO DE CÁLCIO, COBRE, CROMO, FERRO, MAGNÉSIO, MANGANÊS, POTÁSSIO, SÓDIO E ZINCO EM ETANOL POR ESPECTROMETRIA DE ABSORÇĀO ATÔMICA
}

\author{
ELISABETE A. DE NADAI FERNANDES
}

Orientador: HENRIQUE BERGAMIN FILHO

Dissertação apresentada à Escola Superior de Agricultura "Luiz de Queiroz", da Universidade de São Paulo, para obtenção do título de Mestre em Energia Nuclear na Agricultura.

PIRACICABA

Estado de São Paulo - Brasil

Novembro - 1981 
A meus pais, Pedro e Nair, e a meus. filhos, Mesly e Erik, $D E D I C O$.

A Francisco José Krug e

Epaminondas S.B. Ferraz, pela dedicação constante $e$ coniga, OFERE\&O. 
. $i$.

AGRADECIMENTOS

"... a cada um segundo

as suas obras".

Mateus, $16: 27$. 
.ii.

INDICE

Pägina

RESUMO

vii

SUMMARY

$i x$

1. INTRODUÇÃO . . . . . . . . . . . . . . . . 01

2. REVISÃO BIBLIOGRĀFICA . . . . . . . . . . . 06

2.1. Determinação de metais em bebidas alcoólicas..... 07

2.2. Determinação de metais usando solventes orgânicos . . 10

2.3. Determinação de metais em etanol . . . . . . . 17

3. MATERIAL E METTODO ......................... 19

3.1. Material ......................... 19

3.1.1. Instrumentos e Acessórios . . . . . . . 19

3.1.2. Reagentes e Soluções . . . . . . . . 19

3.1.3. Amostras .................. 21

3.2. Mētodo ........................ 22

3.2.1. Considerações Gerais . . . . . . . . 22

3.2.2. Escolha da Chama ........... 26

3.2.3. Estudo da Razão Acetileno-Ar . . . . . . 27

3.2.4. Estudo da Posição Relativa do Queimador .... 29

3.2.5. Estudo da Influência do Grau Alcoólico das Amos tras........................... 31

3.2.6. Características Analíticas ........ 33 
.ii.

Pägina

3.2.6.1. Precisão . . . . . . . . 33

3.2 .6 .2 . Exatidão ............. 34

3.2.6.3. Limite de Deteção . . . . . . 35

3.2.6.4. Sensibilidade . . . . . . 36

4. RESULTADOS E DISCUSSÃO . . . . . . . . . . . . 37

4.1. Estudo da Razão Acetileno-Ar . . . . . . . 37

4.2. Estudo da Posição Relativa do Queimador ....... . 45

4.3. Es tudo da Influência do Grau Alcoólico das Amostras . . 50

4.4. Características Analíticas .......... 55

4.4.1. Precisão ............... 55

4.4.2. Exatidão ................. 55

4.4.3. Limite de Deteção . . . . . . . . . 56

4.4.4. Sensibilidade . . . . . . . . . . 56

5. CONCLUSÕES .......................... 69

6. LItERATURA CITADA .................... 71 
.iv.

\section{LISTA DAS TABELAS}

Tabela

1 Parâmetros instrumentais recomendados pelo fabricante do es pectrômetro de absorção atômica. (Perkin Elmer, 1974). ...

2 Melhores condições experimentais encontradas para mistura acetileno-ar e altura do queimador. . . . . . . . . .

3 Parâmetros da correlação linear entre o logaritmo natural da absorbância ( $\operatorname{nA}$ ) e o grau alcoólico (GL) com condições experimentais de razão de gases e altura do queimador dadas

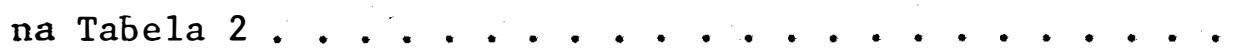

4 Precisão da análise expressa pelo desvio padrão relativo $\left(s_{p}\right)$, para 20 repetições e dois níveis de concentração. As condições experimentais de razão de gases e altura do quei mador são dadas na Tabela $2 . . . . . . . . .458$

5 Teste de recuperação de magnésio. . . . . . . . . . 59

6 Teste de recuperação de sódio . . . . . . . . . . . . 60

7 Teste de recuperação de zinco . . . . . . . . . . . 61

8 Teste de recuperação de potássio . . . . . . . . . 62

9 Teste de recuperação de cobre . . . . . . . . . . 63

10 Teste de recuperação de ferro . . . . . . . . . . . 64 
11 Curvas de padronização para os elementos em etanol absoluto $(99,8 \% \mathrm{v} / \mathrm{v})$, sob condições experimentais de fluxo de gases e altura do queimador dados na Tabela 2 e comprimento de on da e corrente de lâmpada dados na Tabela 1........ 65

12 Curvas de padronização para os elementos em āgua, sob condi ções experimentais de fluxo de gases e altura do queimador dados na Tabela 2 e comprimento de onda e corrente de lâmpa da dados na Tabela 1. . . . . . . . . . . 66

13 Limite de deteção e sensibilidade da determinação dos ele

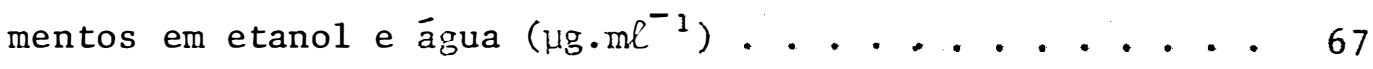

14 Concentrações características dos elementos em etanol e āgua . . . . . . . . . . . . . . . . . . . 


\section{LISTA DE FIGURAS}

Figura

1 Curvas de absorbancia dos elementos em etanol absolu to $(99,8 \% \mathrm{v} / \mathrm{v})$ em função da razão acetileno-ar. 0 fluxo de ar e a altura do queimador foram fixados nos valores dados na Tabela 2 para cada elemento . . .

2 Curvas de absorbância dos elementos em āgua em fun ção da razão acetileno-ar. o fluxo de ar e a altura do queimador foram fixados nos valores dados na Tabe 1a 2 para cada elemento . . . . . . . . .

3 Perfil de absorbância dos elementos em etanol absolu to $(99,8 \% \mathrm{v} / \mathrm{v})$ em relação à altura (H) do queimador. Os fluxos de acetileno e de ar para cada elemento

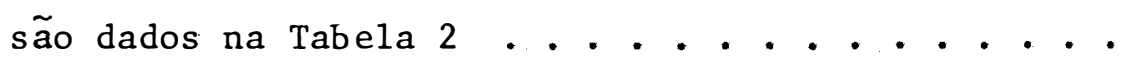

4 Perfil de absorbância dos elementos em água em rela ção à altura (H) do queimador. Os fluxos de acetile no e de ar para cada elemento são dados na Tabela 2. 
Determinação de cālcio, cobre, cromo, ferro, magnēsio, manganês, potās sio, sōdio e zinco em etanol por espectrometria de absorção atômica.

Elisabete A. De Nadai Fernandes

Orientador: Henrique Bergamin Filho

RESUMO

Foram estudadas as melhores condições analíticas de deter minação de ferro, cobre, cromo, cálcio, magnésio, sódio, manganês, zinco e potássio em etanol absoluto, $99,8 \%$ v/v, por espectrometria de absorção atômica, com chama de ar-acetileno.

Os fluxos dos gases componentes da chama e a altura do queimador em relação ao feixe ótico foram otimizados para cada elemento. Observou-se que existe uma razão acetileno-ar e um perfil característico de distribuição vertical dos átomos no estado fundamental para cada ele mento.

Constatou-se uma influência significativa da variação do grau alcoólico das amostras de etanol sobre a sensibilidade das determi nações. Obteve-se para cada elemento uma curva de regressão reprẹ sentativa da variação da absorbância com o grau alcoólico na faixa de 90 a 99,8\%, em um nível de concentração do elemento.

A avaliação das características analíticas do método se guiram as normas preconizadas pela IUPAC, 1978. A precisão foi avalia- 
-veu.

da em duas concentrações dos elementos, observando-se um desvio padrão re lativo máximo de 4,5\% para baixas concentrações $\left(0,02\right.$ a $\left.0,1 \mu g \cdot m \ell^{-1}\right)$ e de $0,45 \%$ para concentrações dez vezes mais elevadas.

A exatidão foi estimada por testes de recuperação em di versas amostras de etanol, que apresentavam concentrações mensuráveis dos elementos em estudo. Em todos os casos, constatou-se que a recuperação média foi de $100 \%$.

As curvas de padronização apresentaram boa linearidade na faixa de concentração estudada e a sensibilidade e o limite de deteção foram extraídos diretamente da curva. A sensibilidade da determinação de metais em etanol foi em geral 2 - 3 vezes superior àquela obtida para ăgua. 
.ix.

Determination of calcium, copper, chromium, iron, magnesium, manganese, potassium, sodium and zinc in ethanol by atomic absorption spectrometry.

Elisabete A. De Nadai Fernandes

Adviser: Henrique Bergamin Fitho

\section{SUMMARY}

The direct determination of calcium, copper, chromium, iron, magnesium, manganese, potassium, sodium and zinc in ethanol by atomic absorption spectrometry with air-acetylene flame is proposed. Effects of fuel/oxidant ratio, burner height and water content in the samples were investigated in detail. The method allows the determination of the elements with good precision ( .s.d. < 4.5\% for low concentrationd and good accuracy (mean recoveries of $100 \%$ after standard additions).

The limits of detection ranged from 0.0004 to $0.0088 \mu \mathrm{g} \cdot \mathrm{ml}^{-1}$ for the elements tested. 


\section{INTRODUÇÃO}

o etanol, composto orgânico de fórmula simplificada, $\mathrm{C}_{2} \mathrm{H}_{5} \mathrm{OH}$, è o segundo solvente em uso, depois da āgua, afirmam PALACIO LLA MES (1956) e MONICK (1968). Industrialmente, pode ser obtido por via sin tética ou biolögica, através da fermentação de produtos agrícolas, apre sentando este ūltimo sistema grande importância na economia brasileira. O termo álcool é utilizado na prática para designar uma mistura etanolágua, sendo que a proporção entre estas duas substâncias e o teor de ele mentos secundārios definem os diversos tipos de ālcool no mercado: āl cool anidro ou absoluto, álcool hidratado ou carburante, álcool retifica do industrial, fino ou extra-fino, ālcool bruto ou de segunda, etc.

Sua aplicabilidade se estende às mais variadas atividades humanas, podendo ser dividida principalmente nas seguintes āreas de inte resse:

industrial: como solvente nas indūstrias química, farmacêu tica e de cosméticos.

alimentícia: principalmente em bebidas e licores. 
alcoolquỉmica: como matéria-prima para os mais diversificados prodıtos: eteno, derivados acéticos, derivados halogenados, éteres, ésteres etí licos e butílicos, obtenção de borracha sin tética, entre outros.

combustível: utilizado tanto em mistura com a gasolina, au. mentando sua octanagem, como na alimentação direta de motores à álcool.

Estando o Brasil atualmente vivendo a redescoberta do álcool como combustível para veículos motorizados, notável interesse tem sido despertado na ārea da química analítica do produto, na tentativa de se verificar os metais presentes e sua possível ação corrosiva sobre as ligas metālicas em uso. Neste particular, estudos de cinética de corro são em componentes de automóveis (tanques de armazenamento, böias de tan ques, carburadores e filtros) vem sendo realizados. Ainda, a crescente importância do etanol como matéria prima para a produção de eteno, onde o conhecimento e o controle das impurezas presentes são de caráter funda mental, justifica um estudo mais aprofundado de sua composição (BR̈̈NING e MALM, 1980L.

A origem dos elementos metálicos contidos no etanol, pro duzido por via biológica, é presumivelmente devida a várias fontes, as sim reunidas:

a) aqueles elementos que fazem parte da composição bioló gica da matéria prima, tais como potássio, magnésio, 
cálcio, sódio e os micronutrientes ferro, zinco, manga nês, cobre, cobalto e molibdênio.

b) aqueles de natureza tecnológica, provenientes:

- dos tratamentos químicos da planta, como os insetici das e fungicidas contendo cobre e chumbo;

- dos diversos materiais com os quais o álcool entra em contato, durante o processamento e armazenamento, principalmente devido ao desgaste da maquinaria, que pode contribuir com a presença de cobre, zinco, estanho, ferro e alumínio;

- das impurezas presentes nos reagentes químicos que entram no processo de fabricação, citando-se os agen tes desidratantes como o benzeno, a benzina, o desi dratol, o ciclohexano, os agentes desnaturantes como o azul de metileno, cânfora, piridina, e os agentes neutralizantes como o hidróxido de sōdio (STUPIELLO et alii, 1973).

GOUX (12751, em sua discussão a respeito da determinação de elementos metálicos em combustíveis derivados de petróleo, cita aígu mas das especificações em relação aos limites máximos permissíveis para vanādio, sódio, potássio, cálcio e chumbo. A ação corrosiva do vanádio sobre as ligas metálicas é parcialmente neutralizada pela presença de magnésio, devido à formação de compostos de alto ponto de evaporação. Já em presença de sódio e potássio, o efeito é acelerado, produzindo compos 
tos eutéticos que se fundem a baixas temperaturas $\left(566^{\circ} \mathrm{C}\right)$. O cálcio vai facilitar a formação de depósitos sólidos de difícil remoção, mesmo atra vés de lavagens com água, e o chumbo tende a anular o efeito depressivo do magnésio sobre a corrosão.

Por outro lado, o único i tem de especificação técnica, es tabelecído pelo Instituto do Açúcar e do Ālcool, conforme o Ato no 14/80 de 03 de julho de 1980, refere-se ao teor máximo de cobre, fixado em 0,07 ppm, unicamente para o álcool etílico anidro combustível. Entretanto, ob. servou-se em relatórios de reuniões do corpo técnico do Conselho Nacional do Petrōleo (CNP), responsável por estas especificações, a sugestão de se programar novos estudos para a avaliação das impurezas presentes no álcool etílico, como base para futuras especificações para o álcool etí lico de fins combustíveis.

Face às considerações expressas, denota-se a importância prática do estudo desses elementos, para que se possam especificar nor mas de controle, em termos de limites máximos permissíveis, de acordo com a finalidade a que se destina o etanol.

Notando-se a insuficiência de metodologia específica para a análise de componentes inorgânicos em etanol e verificada a sua viabí lidade, propõe-se a espectrometria de aநsorção atômica, por aspiração di reta da amostra, sem nenhum tratamento prévio, por ser um método de gran de interesse, devido principalmente a sua simplicidade e seu potencial em meio orgânico tanto quanto o aquoso. 
.05 .

o objetivo, entretanto, não é estabelecer um método analí tico definitivo, mas permitir o desenvo?vimento de procedimentos detalha dos de problemas particulares com os instrumentos existentes. 
.06 .

\section{REVISÃO DE LITERATURA}

Desde 1955, quando WALSH, na Austrālia, e ALKEMADE et aliz; na Holanda, desenvolveram os primeiros métodos de determinação de metais por espectrometria de absorção atômica, esta técnica tem sido aplicada com sucesso para a análise de tecidos vegetais, solos, ligas metálicas, minérios, tecidos animais, águas naturais, bebidas, entre outros mate riais. Entretanto, com relação a determinação de metais em ālcoois, mais especificamente em etanol, poucas referências foram encontradas, e os trabalhos se acham diversificados na literatura, conforme o emprego do etanol nos diferentes setores.

Desta forma, a presente revisão destacou alguns trabalhos de importância realizados nas áreas de bebidas alcoólicas e de solventes orgânicos, de modo a permitir uma melhor compreensão dos fenômenos que concorrem para um aumento de sensibilidade, assim como fornecer subsídios a um procedimento metodológico capaz de definir as melhores condições pa ra a determinação de metais em etanol. 


\title{
2.1. Determinação de metais em bebidas alcoōlicas
}

\begin{abstract}
A determinação de metais em vinhos por AAS foi primeira mente descrita por ZEEMAN e BUTLER (1962), salientando as vantagens des te método em relação aos colorimétricos tradicionais, bastante morosos e difíceis. Porēm, as amostras eram antes evaporadas e incineradas, sendo retomadas em ācido, obtendo-se um fator de concentração de 25 vezes, su ficiente para a determinação das mais baixas concentrações. Entretanto, a anālise direta, sem preparo prévio, foi desenvolvida anos mais tarde, como destacam os trabalhos a seguir.
\end{abstract}

Assim, SLAVIN (1965) observou que, na determinação de co bre e ferro em vinhos, a presença do ālcool é responsável por um aumento na sensibilidade, ao redor de $35 \%$, quando comparada àquela obtida em so luções aquosas. Face à variação do grau alcoólico das amostras, o autor utilizou o método das adições padrão, a fim de obter resultados mais pre cisos .

Dois anos mais tarde, STRUNK e ANDREASEN propuseram a AAS para a determinação de cobre em uísque, conhaque e rum, entre outras be bidas, por aspiração direta das amostras. Observaram a necessidade de preparar soluções padrão, apresentando a mesma viscosidade das amostras. Para tanto, uma vez que a graduação alcoólica das amostras variou entre 20,0 e 44,5\% v/v, utilizaram soluções padrão preparadas em etanol $50 \% \mathrm{v} / \mathrm{v}$. As condições analíticas utilizadas foram aquelas recomendadas pelo fabri cante do instrumento e os resultados apresentaram boa concordância com o método colorimétrico da AOAC. 
Em 1968, HOFFMAN et alii estabeleceram a composição ele mentar de 151 amostras de destilados produzidos ilicitamente, através da anālise por ativação neutrônica e AAS. Nesta ūitima técnica, as amos tras foram nebulizadas em chama de ar-hidrogênio, para se determinar quan titativamente cádmio, cālcio, cobre, cromo, chumbo, ferro, potássio, mag nésio, manganês, sódio, estrôncio e zinco. Os autores utilizaram solu ções-padrão de grau alcoólico semelhante ao encontrado nas amostras, pa ra evitar os efeitos da variação do solvente orgânico nas medidas efe tuadas.

Os efeitos da concentraçao de ālcool na determinação de cáłmio, chumbo, cobalto, cobre, cromo, níquel e zinco em vinhos foram investigados por MÉRANGER e SOMERS (1968). 0 aumento do teor de etano1 de 0 a 50\%, na solução padrão multielementar dos metais citados, resul tou em mudanças pronunciadas na linha de base, ao lado de um aumento na sensibilidade. As alterações na linha de base introduziam muitos erros na anālise, a não ser que parâmetros instrumentais, como relação combu rente-combustível e taxa de aspiração, fossem otimizados com solu ções-padrão contendo a mesma concentração alcoōlica de cada vinho amostra do. Os autores consideraram como técnica mais simples, a remoção do ā1 cool por evaporação, como preconiza o procedimento oficial da $A O A C$ (1965). Observaram também que dos metais testados a alteração da linha de base foi negligível apenas para o cobre, em concentrações de ālcool abaixo de $50 \% \mathrm{v} / \mathrm{v}$, explicando, assim, o êxito dos trabalhos de SLAVIN (1905) e STRUNK e ANDREASEN (1967).

Em 1970, MEREDITH et alii, após um estudo detalhado sobre 
métodos de determinação de ferro em bebidas alcoōlicas, recomendaram a técnica de absorção atômica, por ser mais rápida, exata e precisa que os métodos convencionais. As amostras foram nebulizadas em chama de ar-ace tileno, observando-se rigorosamente o teor alcoōlico das amostras. Bebi das com graduação alcoólica variando entre $43-45 \% \mathrm{v} / \mathrm{v}$ foram lidas con tra uma curva de padronização preparada em etano1 43\% v/v. Entretanto, para produtos a $50 \% \mathrm{v} / \mathrm{v}$, outra série de padrões foi preparada em etanol $50 \%$ ou, quando conveniente, as amostras eram diluídas a $43 \% \mathrm{v} / \mathrm{v}$. Para a anālise de vinhos a $20 \% \mathrm{v} / \mathrm{v}$, elevaram o grau alcoólico para $43 \% \mathrm{v} / \mathrm{v}$, por diluição adequada das amostras com etanol $95 \% \mathrm{v} / \mathrm{v}$.

En 1972, VARJU comparou dois métodos de preparo de amos tra para a determinação de cobre, ferro e magnésio em conhaque, usando chama de ar-acetileno: (1) aspiração direta da amostra e (2) oxidação prê via, retomando o resíduo em água. No primeiro método, um ajuste do grau alcoōlico das amostras era feito a $50 \% \mathrm{v} / \mathrm{v}$, quando as mesmas estivessem fora dos 1 imites de $47-53 \% \mathrm{v} / \mathrm{v}$. As curvas de padronização foram prepara das em etanol $50 \% \mathrm{v} / \mathrm{v}$ e os resultados mostraram que a exatidão não é afe tada significativamente, se o teor alcoólico variar menos que $5 \%$ em tor no deste valor. Ln desvio padrão relativo de 3 a $7 \%$ foi observado entre os dois métodos, sendo maior para baixas concentrações do metal. Entre tanto, as diferenças relativamente pequenas mostraram que havia pouco e feito de matriz nas amostras, tornando desnecessāria a mineralização pre liminar das mesmas. Além disso, verificou que, trabalhando com soluções alcoōlicas a $50 \% \mathrm{v} / \mathrm{v}$, a sensibilidade apresentou um ganho aproximado de $100 \%$ sobre aquela obtida em soluções aquosas. 
Dois anos depois, GEGIOU e BOTSIVALI (1975) determinaram chumbo em vinhos e outras bebidas por aspiração direta das amostras em chama de ar-acetileno. A sensibilidade do método proposto é menor do que a dos métodos que envolvem procedimentos de concentração, mas apresen tam a vantagem de grande simplicidade e rapidez, com exatidão e precisão comparáveis. O efeito das diferentes matrizes das amostras sobre a absorção foi investigado pela adição de quantidades conhecidas de chumbo. o decréscimo na taxa de aspiração observado para os vinhos, em relação à da solução aquosa de mesma concentração, era compensado por um igual au mento na absorção do chumbo, atribuído à presença de etanol nas amostras. Assim, foi estabelecida uma correlação entre a absorção e taxa de aspira ção com concentrações crescentes de etanol. Una vez que a absorção do chumbo aumentava efetivanentecom o acréscimo de etanol, e como existia uma variação no teor alcoólico das amostras, recorreram ao método das adições para se proceder às determinações.

\subsection{Determinação de metais usando solventes orgānicos}

Segundo THOMPSON e REYNOLDS (1978), o uso de solventes or gânicos miscíveis com água foi, até 1968, a prática mais comumente empre gada para aumentar a sensibilidade da análise de um elemento. Diversos álcoois, entre eles, o etílico e o isopropílico, juntamente com a aceto na, foram os solventes de maior aplicação, inclusive na determinação de 
metais que formam óxidos refratārios na chama. Entretanto, com o desen volvimento dos equipamentos de absorção atômica, possibilitando um aumen to significativo na sensibilidade, este procedimento tornou-se menos fre quente.

Em 1960, ROBINSON observou que solventes orgânicos aumen tavam tanto a emissão como a absorção da linha espectral $341,4 \mathrm{~nm}$ do ní quel. 0 estudo foi realizado em soluções contendo 50 ppm de níquel em dezessete solventes, incluindo o etanol, nebulizados em chama de oxicia nogênio. O autor comenta que o ganho na absorção não pode ser justifica do apenas pelo acréscimo de temperatura da chama, uma vez que o nümero de átomos no estado fundamental tende a decrescer com temperaturas eleva das. Além disso, salientou que, como os solventes orgânicos são queima dos com facilidade, um número maior de átomos no estado fundamental é for mado na chama por unidade de tempo. Paralelamente, des de que os solven tes orgânicos evaporam mais facilmente do que a água, o processo de for mação de ātomos no estado fundamental torna-se mais eficiente, aumentando, consequentemente, a sensibilidade.

Un aumento relativo na sensibilidade analítica da determi nação de cobre, ferro, manganês, zinco e magnésio, adicionando solventes orgânicos às soluções aquosas desses elementos, foi também verificado por ALLAN (1961l. Várias misturas de solventes foram nebulizadas em chama de ar-acetileno e o fluxo do combustível foi ajustado, em cada caso, para manter o mesmo tamanho e forma da chama com todos os solventes usados. Aspirando soluções $40 \% \mathrm{v} / \mathrm{v}$ de metanol, etanol, isopropanol e acetona, a sensibilidade foi praticamente duplicada, comparada àquela oḅtida para soluções aquosas puras. 0 autor concluiu que este efeito é devido, prin 
cipalmente, ao aumento da quantidade de solução que alcança a chama (maior taxa de aspiração, aerosol mais finominimizando a condensaçãa, eva poração mais rápida do solvente) e, em segundo lugar, à pequena redução de temperatura da chama (redução do efeito Doppler e aumento da concen tração atônica na chama, pela diminuição do volume de gases).

LOCKYER et alii (1961) procuraram aumentar a sensibilidade da determinação de certos cátions em AAS, em chama de ar e gás de car vão. Foi investigado o efeito de concentrações crescentes de uma série de álcoois (metanol, etanol, propanol, butílico e amílico) sobre a absor bância de magnésio, níquel, césio, prata, cálcio, ferro e zinco. Verifi caram um aumento da absorbância com a concentração alcoólica, sendo que para o propanol a estabilização foi alcançada a $50 \% \mathrm{v} / \mathrm{v}$. Para este ū1tí mo solvente, nesta concentração, as sensibilidades relativas dos elemen tos diferiram bastante, indicando que o efeito não é devido somente às mudanças na tensão superficial e viscosidade. Os autores sugeriram, en tão, que o aumento de sensibilidade pode ser atribuído às prováveis alte rações nas condições momentâneas da chama, quando o solvente das gotícu las è evaporado.

O efeito da liberação química dos àtomos na chama foi ve rificado por ROBINSON e KEVAN (1963), com soluções 10 ppm de cromo, pre paradas a partir de sais orgânicos e inorgânicos, em àgua, etanol, benze no e etanol-benzeno $(50: 50)$. Os resultados indicaram que para soluções organo-metālicas um maior sinal de absorção é obtido, suportando a tese de que a população de átomos metálicos em uma chama é aumentada pelo uso de solventes orgânicos e de compostos organo-metālicos. Ainda mais, que 
compostos organo-metālicos em soluções orgânicas proporcionam a máxima absorção e soluções inorgânicas aquosas, a menor sensibilidade. Assim, para uma sensibilidade máxima, o metal deve estar em um solvente orgâni co e na forma de um composto organo-metálico de fácil decomposição.

DAGNALL e WEST (1964) investigaram o efeito de alguns sol ventes orgânicos miscíveis com água na determinação de chumbo por AAS, em chama de ar-propano. Soluções $100 \mathrm{ppm}$ de chumbo contendo $10 \% \mathrm{v} / \mathrm{v}$ de me tanol, etanol, propanol, acetona,metil-etil cetona, ácido acético e dioxa no tiveram suas absorbâncias aumentadas (de 22 a 54\%) com relação à da água, fato este atribuído a um aumento na eficiência de vaporização. En tretanto, com os solventes etileno glicol e glicerol, observaram um efe $\underline{i}$ to contrário (decréscimo de 11 e $20 \%$, respectivamente), devido ao aumen to da viscosidade das soluções.

Āgua, etanol, éter, acetona e metil-isobutil cetona foram os solventes estudados por FELDMAN e PURDY (1965), para a obtenção da má xima sensibilidade na determinação de cromo por AAS, em chamas de oxi-hí drogênio e ar-hidrogênio. Após definirem limite de deteção. como a con centração de cromo necessária para produzir um sinal de absorção de 5\%, com relação à prova em branco, este sinal foi tomado como referência pa ra a escolha do solvente mais apropriado. Os resultados mostram uma di ferença não muito significativa entre os limites de deteção para etanol $(0,030 \mathrm{ppm})$ e àgua $(0,038 \mathrm{ppm})$, em comparação com metil-isobutil cetona (0,006 ppm), em chama de ar-hidrogênio. Os autores concluíram que esta chama foi muito mais sensivel nas determinações do que a chama de oxi-hi drogênio, o que era de se esperar pelos princípios teóricos de AAs, refe 
rentes à temperatura e número de átomos no estado fundamental.

Un estudo da sensibilidade de determinação de manganês por AAS, usando quatro solventes, foi realizado por FELDMAN et alii (1967). As soluções foram aspiradas em chama de ar-hidrogênio, ajustando o fluxo dos gases e a altura do queimador para cada solvente utilizado. As con centrações de manganês, para um sinal de $5 \%$ de absorção, foram $25,1,3$ e $15 \mathrm{ppb}$ para água, acetona, metîl-isobutil cetona e etanol, respectivamente. Os autores encontraram uma relação linear entre a absorbância das soluções 100 ppm de manganês nos solventes testados e o produto da densi dade pela viscosidade. Afirmaram ainda que com esta relação pode-se pre dizer a absorbância para outros solventes ou, então, obter uma aproximação da viscosidade, se os outros parâmetros forem conhecidos.

os metais refratários, como alumínio, berílio, silício, ti tânio, tungstênio, vanádio e outros, foram originalmente catalogados por ELWELL e GIDLEY (1962), entre os elementos não determinados por AAS. Entretanto, SACHDEV et alii (1967)afirmararn que a determinação desses ele mentos tornou-se possível, com a utilização de solventes orgânicos. So luções 1000 ppm de vanádio em concentrações crescentes de metanol, etanol e propanol foram aspiradas em chama de oxi-acetileno, com composição variada. A absorção máxima foi obtida em chamas altamente redutoras, com uma concentração do solvente acima de $70 \% \mathrm{v} / \mathrm{v}$. Assim, soluções de vaná dio, preparadas apenas com os solventes puros $(98 \% \mathrm{v} / \mathrm{v})$, tiveram suas ab sorbâncias comparadas, possibilitando a escolha do solvente mais apropria do à maximização do sinal de absorção. Do mesmo modo, soluções etanólí cas com adições variadas de compostos orgânicos (dioxano, tolueno, gli 
cerina, etileno glicol e ácido olêico) indicaram que o sinal de absorção aumenta com o ponto de ebulição e com a cadeia de carbono destes compos tos adicionados. Os autores atribuem este acréscimo na absorção, ou na eficiência de produção de átomos metálicos, ao decréscimo do tamanho das partículas do aerosol, ao calor de combustão do solvente e às condições bastante redutoras estabelecidas na chama pelo uso de solventes orgâni cos.

Em 1968, POPHAM e SCHRENK estudaram as características da absorção atômica do germânio em chamas de oxiacetileno e óxido nitroso-a cetileno, observando o efeito de solventes orgânicos, razões combustí vel/oxidante e a posição relativa do feixe na chama. Soluções 100 ppm de germânio em soluções $50 \% \mathrm{v} / \mathrm{v}$ de acetona, metanol, etanol e isopropa nol apresentaram um ganho de absorção de $50 \%$ a $100 \%$ com relação à solu ção aquosa de mesma concentração. Os valores de absorção obtidos em cha ma de óxido nitroso-acetileno foram, aproximadamente, sete vezes maior do que aqueles obtidos em chama de oxiacetileno. Sensibilidades máximas foram obtidas em chamas redutoras, o que era esperado devido à energia de dissociação relativamente alta do $\operatorname{GeO}(5,5 \mathrm{eV})$ e à redução da forma ção de monóxidos metálicos. Uñ estudo de interferências de diversos cá tions e ânions na determinação do germânio mostrou que o efeito é signni ficativamente maior para acetona comparado ao da àgua, contrariando o efeito benéfico de redução de interferências atribuído aos solventes or gânicos (maior temperatura e menor tamanho de partículas).

HARRISON e JULIANO (1969) observaram um efeito depressivo sobre a absorbância do estanho com a presença de ālcoois, cetonas e áci 
dos orgânicos, em chama redutora de ar-hidrogênio. Diversos perfis de absorbância foram levantados com 0,20 e $80 \% \mathrm{v} / \mathrm{v}$ de metanol, etanol, pro panol e butanol. Verificou-se que, à medida que a concentração alcoóli ca aumenta, há um decréscimo na absorbância do estanho, acompanhado de um deslocamento do pico de absorbância para uma posição mais alta na cha ma. Solventes orgânicos parecem reduzir a população efetiva de átomos de hidrogênio na chama, produzindo uma queda na população atômica do es tanho. Outros elementos foram estudados nas mesmas condições, observan do-se o mesmo efeito para bário e magnésio, ao passo que para ferro, co bre e zinco houve um significativo aumento da absorbância. Entretanto, o mesmo experimento, em chama redutora de ar-acetileno, resultou num acrês cimo da absorbância para o estanho, bário e magnésio.

PANDAY e GANGULY (1970) ressaltaram o uso de alguns sol ventes orgânicos miscíveis com a água, objetivando a redução de interferências químicas e um aumento na sensibilidade analítica dos métodos de absorção atômica. Diferentes proporções de metanol, etanol e acetona fó ram adicionadas às soluções aquosas de cobre, manganês, ferro, zinco e rubídio (em chama de ar-acetileno) e de cálcio e magnésio (em chama de óxido nitroso-acetileno). Pelos resultados apresentados, verifica-se que - ganho de sensibilidade (expresso como a relação entre a absorbância da mistura do solvente orgânico e àquela obtida para solução aquosa, à mesma concentração do elemento) aumenta com a concentração do solvente e apresenta uma tendência a diminuir com o aumento da concentração do ele e mento. Os autores concluírmque a razão básica para a redução das inter ferências pode ser a formação de partículas menores, que se decompõem mais rapidamente e em mais alto grau do que as maiores. 
SZIVOS et alii (1976) estudaram os parâmetros da nebuliza ção, para explicar o aumento da sensibilidade de AAS, devido ao uso de solventes orgänicos. A relação existente entre taxa de aspiração (tempo necessário para nebulizar $2 \mathrm{~m} \ell$ do solvente) e eficiência de nebulização (fração do aerosol formado, que atinge a chama, determinado a partir de um dispositivo especial, desenvolvido pelo próprio autor) é mostrada pa ra água, etanol, n-butil-acetato e metil-isobutil cetona. Observaram que a nebulização torna-se mais efetiva com o decréscimo da taxa de aspira ção, e vice-versa, existindo uma relação hiperbólica entre esses dois pa râmetros, se os outros permanecerem constantes. Assim, o volume de aero sol (produto da taxa de aspiração pela eficiência de nebulização) que che ga à chama é praticamente constante. A sensibilidade relativa da deter minação de chumbo para os três grupos de solventes (álcoois, cetonas e acetatos orgânicos) diminui com o conteúdo de carbono no radical, aumen tando, porém, com o conteúdo total de carbono do solvente, ou seja, á1coois, cetonas e acetatos, respectivamente. Os autores afirmam ainda que, apesar de o tamanho médio das partículas para os solventes orgânicos ser menor do que o da água, o aumento de sensibilidade não pode ser interpre tado com base neste argumento.

2.3. Determinação de metais em etanol

BRÜNING e MALM (1980) a presentam uma análise qualitativa por fluorescência de raio-X, efetuada em amostras de etanol de diversas procedências. Neste levantamento preliminar, os elementos foram caracte zados em ausentes (fósforo) e presentes (enxôfre, zinco, cobre, ferro, manganês, cromo, titânio, cálcio, potássio, cloro, silício, alumínio e 
chumbo). A seguir, foram analisados quantitativamente por AAS, apenas os elementos cujos teores e características pudessem ameaçar os cataliza dores do processo de obtenção do eteno. Assim, os níveis de ferro, ní quel, cobre, cromo, potássio e sódio foram determinados, tantó no resí duo como no filtrado, sendo que este foi previamente concentrado por eva poração à secura e retomado em meio ācido diluído. Dessa maneira, um fá tor de pré-concentração de cerca de 10 vezes permitiu atingir limites de deteção de partes por bilhão. Os resultados mostram uma grande va riação no teor desses metais entre os álcoois amostrados e os autores es tabelecem uma correlação destes elementos com o histórico de produção das amostras . 


\section{MATERIAL E METODO}

\subsection{Material}

\subsubsection{Ins trumentos e Acessōrios}

0 instrumento empregado no estudo foi um espectrômetro de absorção atômica Perkin-Elmer, modelo 306, equipado com painel de contro le de gases, modelo 303-0692, e lâmpadas de catodo oco de ferro, cobre, zinco, potássio, cromo, manganês, sódio e cálcio-magnésio.

Para a determinação do grau alcoólico foi utilizado um densimetro digital PAAR, modelo DMA 46.

\subsubsection{Reagentes e Soluções}

Todos os reagentes foram de qualidade pro-análise, señdo secos em estufa quando necessário, e āgua destilada-deionizada e/ou etạ nol absoluto $99,8 \% \mathrm{v} / \mathrm{v}$, redestilado, foram sempre utilizados.

Soluções estoque

$1000 \mu \mathrm{g} \cdot \mathrm{m} \ell^{-1}$ de ferro: transferiu-se o conteúdo de uma ampola Titrisol- 
-Merck, contendo $1,0000 \mathrm{~g}$ de ferro $\left(\mathrm{FeCl}_{3}\right)$, para um balão volumétrico de $1000 \mathrm{ml}$ e completou-se o volume com água.

$1000 \mu \mathrm{g} \cdot \mathrm{m} \ell^{-1}$ de cálcio: dissolveram-se $2,4973 \mathrm{~g}$ de carbonato de cálcio, $\mathrm{CaCO}_{3}$, em aproximadamente $50 \mathrm{~m} \ell$ de água, adiciona ram-se $10 \mathrm{~m} \ell$ de ácido nítrico concentrado, e di luiu-se a $1000 \mathrm{~m} \ell$ com água.

$1000 \mu \mathrm{g} \cdot \mathrm{m}^{-1}$ de cobre: dissolveu-se $1,0000 \mathrm{~g}$ de cobre metälico em $10 \mathrm{~m} \ell$ de ácido nítrico concentrado, e diluiu-se a 1000 ml com água.

$1000 \mu \mathrm{g} \cdot \mathrm{m} \ell^{-1}$ de magnésio: dissolveram-se $1,6580 \mathrm{~g}$ de óxido de magnésio, Mgo, em $10 \mathrm{~m} l$ de ácido clorídrico concentrado, e diluiu-se a $1000 \mathrm{~m} \ell$ com água.

$1000 \mu \mathrm{g} \cdot \mathrm{m} \ell^{-1}$ de manganês: dissolveram-se $1,8012 \mathrm{~g}$ de cloreto de manganês tetra-hidratado, $\mathrm{MnCl}_{2} \cdot 4 \mathrm{H}_{2} \mathrm{O}$, em $500 \mathrm{~m} \ell$ com água.

1000 ug.m $\ell^{-1}$ de sódio: dissolveram-se $1,2712 \mathrm{~g}$ de cloreto de sódio, $\mathrm{NaCl}$, em $500 \mathrm{~m} \ell$ com água.

$1000 \mu \mathrm{g} \cdot \mathrm{m} \ell^{-1}$ de zinco: dissolveu-se $1,0000 \mathrm{~g}$ de zinco metálico em $10 \mathrm{~m} \ell$ de äcido nítrico concentrado, e diluiu-se a 1000 $\mathrm{m} \ell$ com água.

$1000 \mu \mathrm{g} \cdot \mathrm{m} \ell^{-1}$ de cromo: dissolveram-se $2,8281 \mathrm{~g}$ de dicromato de potássio anidro, $\mathrm{K}_{2} \mathrm{Cr}_{2} \mathrm{O}_{7}$, em aproximadamente $200 \mathrm{~m} \ell$ de água, adicionaram-se 5,0 ml de ácido nítrico con 
centrado, e diluiu-se a 1000 m $\ell$ com água.

$1000 \mu \mathrm{g} \cdot \mathrm{m} \ell^{-1}$ de potássio: dissolveram-se $1,9069 \mathrm{~g}$ de cloreto de potássio, $\mathrm{KCl}$, em 1000 m $\ell$ comágua.

Soluçöes $100 \mu \mathrm{g} \cdot \mathrm{ml}^{-1}$ de cada elemento em etanol

Transferiram-se $10 \mathrm{~m} \ell$ da solução estoque do elemento a ser determinado para balão volumétrico de $100 \mathrm{~m} \ell$ e completou-se o volume com etanol, observando-se um tempo de espera para que os efeitos resultantes da mistura hidroalcoólica se processassem totalmente (contração de volü me, mudanças de temperatura e liberação de bolhas de ar).

Soluçöes padrāo de trabalho

Prepararam-se, por diluições adequadas da solução 100 $\mu \mathrm{g} \cdot \mathrm{m} \ell^{-1}$ do elemento desejado, soluções padrão na faixa de 0,000 a 2,000 $\mu \mathrm{g} \cdot \mathrm{m} \ell^{-1}$ em etanol.

As soluções padrão de trabalho em àgua foram preparadas na mesma faixa de concentração, por diluições apropriadas das soluções es toque.

\subsubsection{Amos tras}

Diversas amostras de etanol anidro e hidratado, proceden tes de diversas usinas do Estado de São Paulo, foram coletadas e forneci das pela Cooperativa Central dos Produtores de Açúcar e Âlcool do Estado de São Paulo (Copersucar). 


\subsection{Mētodo}

\subsubsection{Considerações Gera is}

Sendo o etanol um solvente orgânico, grandes modificações ocorrem na chama em condições normais de operação para solvente aquoso. Desse modo, as variáveis instrumentais devem ser otimizadas, propiciando a máxima absorbância, para que a concentração de um elemento seja obtida com a maior sensibilidade. Com este objetivo, é bastante usual variar ape nas um parâmetro por vez, enquanto os outros permanecem constantes. Es te procedimento experimental é vālido, conquanto a variável em observação não sofra interação com mais de um parâmetro ao mesmo tempo, permitindo a obtenção de uma série de respostas máximas (RAMIREZ-MUÑOS, 1968). A maioria dos autores estimam estes valores pela alteração de uma ou mais variāveis por vez. Assim, SLAVIN et alii (1963) afirmaram que, ao se es tabelecer uma metodologia para um metal específico em AAS, deve-se, prí meiramente, determinar o efeito dos vārios parâmetros instrumentais. Es tes incluem a escolha da melhor linha analítica de absorção para o ele mento, a largura adequada da janela, a corrente ótima aplicada à lâmpada de catodo oco e os outros värios parâmetros instrumentais. Estes auto res comentam que as discrepâncias existentes entre os resultados de inü meros trabalhos de determinação de cálcio em variadas matrizes podem ser devidas a não normalização dessas condições instrumentais.

Entretanto, CELLIER e STACE (1966) comentam que este método de um fator por vez é bastante moroso, pois muitos ciclos são necessâ rios para se obter as condições ótimas. Propõem, então, a técnica de res posta de superfície, baseada numa sērie de delineamentos fatoriais fra 
cionados, onde a resposta a algumas variāveis ē investigada simultanea mente. As variāveis estudadas para se obter a absorbância máxima da $1 \underline{i}$ nha 422,7 nm do cálcìo, em chama de ar e gàs de carvão, em 3 níveis, um controle e dois tratamentos, foram: concentração, corrente da lâmpada de catodo oco, largura da janela, pressão do ar, fluxo de ar, fluxo do gás e altura acìma do cone azul. Neste método matemático, ficou bastante e videnciado que os fatores críticos para se estimar cálcio por AAS são: fluxo de ar, fluxo de gás, pressão de ar e altura acima do cone, confị mando os resultados obtidos por SLAVIN et alïi (1963), que também obser vou uma dependência marcante entre essas quatro variāveis na determinação do cálcio.

Mais recentemente, INGLE Jr. (1974) apresentou um trata mento teórico dos fatores que afetam a precisão relativa das medições em AAS. A teoria permite predizer como o desvio padrão relativo na absor bância varia com a absorbância e também a contribuição das diferentes fon tes de ruído e parâmetros instrumentais na precisão total, tendo sido comprovado experimentalmente para o cobre (BOWER e INGLE Jr., 1976). As características da precisão de nove elementos (cálcio, cobre, ferro, mag nésio, sódio, zînco, molibdênio, cádmio e arsêniol foram determinadas pe los mesmos autores (1977L, em chamas de ar-acetileno e/ou óxido nitroso -acetileno, e comparadas com as predições teóricas, nas condições instru mentais normais preconizadas pelo manual do instrumento e, em alguns ca sos, em condições diferentes das recomendadas. Obsiervaram que existe uma concordância razoavelmente boa entre a teoria e a experimentação, que di. ferentes fontes de ruỉdo são importantes em diferentes regiões de absorbân 
cia e que as fontes dominantes de ruído, para um dado elemento, podem ser preditas pelo comprimento de onda analítíco.

Já em 1979, BOWER e INGLE Jr. mostraram como a contribui ção relativa de diferentes fontes de ruído e a precisão total das medi ções podem ser afetadas pelas condições instrumentais. As variáveis ins trumentais estudadas foram a intensidade de corrente aplicada à lâmpada de catodo oco, largura da janela, altura da janela, tipo e estequiometria de chama, posição do queimador, linha de ressonância e tempo de integra ção, para obter a melhor razão sinal-ruído. Os autores afirmam que ape sar das medições terem sido realizadas em um determinado instrumento, os resultados indicam as variáveis e procedimentos mais críticos, de forma que outros analistas possam otimizar, eficientemente, as variáveis mais importantes em seus instrumentos particulares. Comentam ainda que as variāveis devem ser otimizadas de acordo com o intervalo de absorbância de. interesse e que os parâmetros recomendados pelos fabricantes não for necem, necessariamente, a precisão ótima em todas as regiões de absorbân cia.

No presente trabalho, os aspectos instrumentais referentes à escolha da linha espectral e ajuste do comprimento de onda, intensida de de corrente fornecida à lâmpada, largura apropriada da janela e tempo de medida, seguîram as recomendações especificadas no manual do instru mento, e acham-se na Tabela 1.

Entretanto, jā que a literatura não fornece informações com respeito à escolha dos gases apropriados, ao melhor ajuste de pressão 
Tabela 1. Parâmetros instrumentais recomendados pelo fabricante do es pectrômetro de absorção atômica (PERKIN ELMER, 1974).

\begin{tabular}{cccc}
\hline Elemento & $\begin{array}{c}\text { Comprimento de } \\
\text { onda (nm) }\end{array}$ & $\begin{array}{c}\text { Intensidade de } \\
\text { Corrente da } \\
\text { Iâmpada (mA) }\end{array}$ & $\begin{array}{c}\text { Largura da } \\
\text { Janela } \\
\text { (mm) }\end{array}$ \\
\hline Ca & 422,7 & 15 & 1,4 \\
Mg & 285,2 & 15 & 0,7 \\
K & 766,5 & 12 & 1,4 \\
Mn & 279,5 & 20 & 0,2 \\
Fe & 248,3 & 30 & 0,2 \\
Cu & 324,7 & 15 & 0,7 \\
$\mathrm{Zn}$ & 213,9 & 15 & 0,7 \\
$\mathrm{Na}$ & 589,0 & 12 & 1,4 \\
$\mathrm{Cr}$ & 357,9 & 20 & 0,7 \\
\hline
\end{tabular}

Tempo de medida para todos os elementos: 6 segundos. 
e fluxo dos gases, ao posicionamento correto do queimador em relação ao feixe ótico e à taxa de aspiração, estes parâmetros foram estudados deta lhadamente, para se proceder à determinação de ferro, cobre, cálcio, zin co, magnésio, potássio, cromo, manganês e sōdio, em etanol.

A concentração das soluções para este estudo foi escolhi da após um levantamento inicial do sinal obtido para cada elemento, pro curando uma concentração que fornecesse uma leitura entre 0,100 e 0,500 unidades de absorbância. A faixa de concentração foi estabelecida entre 0,000 e $2,000 \mu g \cdot m \ell^{-1}$ mediante uma análise preliminar de 73 amostras de etanol de várias procedências, a qual permitiu um conhecimento apro ximado dos teores médios dos diversos metais estudados.

\subsubsection{Escolha da Chama}

Dentre os vários tipos de chama utilizados em absorção atộ mica, escolheu-se a chama de ar-acetileno. Muitos autores propõem o uso desta chama para se determinar os metais em soluções aquosas e orgânicas, devido às facilidades de operação e controle. E uma chama bastante ver sátil, podendo ser operada estequiometricamente ou fracamente oxidante, como na maioria dos casos, ou, então, ajustando-se a taxa de fluxo dos gases, para se obter a absorção máxima para cada elemento, o que aumenta, consideravelmente, a sua aplicabilidade (CHRISTIAN e EELDMAN, 1970; PIN TA, 1975; WEL2, 1976; THOMPSON e REYNOLDS, 1978, entre outros).

A chama de ar-acetileno é completamente transparente numa 
faixa espectral bastante ampla, mostrando, porẻm, uma absorção apreciāvel abaixo de $230 \mathrm{~nm}$, conforme pode ser verificado pelo trabalho de SCHALLIS e KAHN (1968L. Dessa maneira, para a análise de elementos cujas linhas espectrais estejam compreendidas nestes comprimentos de onda, as condi çōes de chama devem ser reprodutíveis, para não comprometer a sensibilidade da determinação, uma vez que a absorção pela chama varia razoave $\underline{1}$ mente com as alterações dos fluxos dos gases.

\subsubsection{Estudo da Razão Acetịteno/Ar}

Segundo RIANDEY (1.75), vários equilíbrios ocorrem em uma chama, dentre os quais, os principais são: a) dissociação (atomização) /combinação; b) dissociação/recombinação e c) ionização/deionização.

Os equilíbrios (a) e (c) dependem particularmente da tem peratura e o equilíbrio (b) é mais influenciado pela composição da chama (oxidante, estequiométrica ou redutora). Dessa forma, é importante ob servar o tipo de combustível e a razão combustível/comburente, no presen te caso, a razão acetileno-ar. Em estudos desta natureza, recomenda-se que o fluxo do oxidante (ar) seja regulado para uma nebulização ótima. 0 mesmo autor lembra que aumentando-se o fluxo de ar, aumenta-se a nebu lização, mas não necessariamente a atomi zação, face a uma diminuição de temperatura. A variação no grau de atomização depende de uma variação no fluxo de acetileno. Assim, em alguns casos, aumentando-se o fluxo do com bustível, a absorbância de um dado elemento aumenta até atingir um valor assintótico e, em outros, passa por um máximo, recomendando-se, na prātí ca, que a escolha do fluxo ótimo de combustível recaia naquele que forne 
cer a maior precisão (menor desvio padrão relativo, vide item 3.2.6.1.).

No presente trabalho, observaram-se as recomendações anteriormente descritas, de acordo com o seguinte procedimento.

Fixaram-se as pressões de ar e acetileno, nas linhas primárias de alimentação da uni dade de controle de gases, em $2,1 \mathrm{~kg} \cdot \mathrm{cm}^{-2} \mathrm{e}$ $0,56 \mathrm{~kg} \cdot \mathrm{cm}^{-2}$, respectivamente. A seguir, realizou-se uma varredura preliminar dos fluxos de ar e acetileno, em torno dos valo res 3,3 e $1,9 \ell \cdot m^{-1}$, respectivamente, re comendados pela PERKIN-ELMER (1974), para solventes orgânicos. Nestas condições, es tabelecido um fluxo de ar que proporcionava a máxima absorbância, variou-se o fluxo de acetileno de 1,9 a $4,1 \ell \cdot \mathrm{min}^{-1}$. A seguir, definido o fluxo de acetileno de mäxima ab sorbância, variou-se o fluxo de ar de 10,4 a $23,8 \ell \cdot \mathrm{min}^{-1}$.

Estes valores foram obtidos com soluções pa drão dos elementos em etanol, preparadas em triplicata, nas seguintes concentrações: fer ro, cobre, cālcio, cromo e manganês- 
$1,0 \mu \mathrm{g} \cdot \mathrm{m} \ell^{-1}$, zinco e potássio-0,5 $\mu \mathrm{g} \cdot \mathrm{m} \ell^{-1} \mathrm{e}$ sódio e magnésio-0,2 $\mu \mathrm{g} \cdot \mathrm{m} \ell^{-1}$. Para todas as intensidades de fluxo testadas, fixou-se a taxa de aspiração em $6,0 \mathrm{~m} l \cdot \min ^{-1}$, e os ou tros parâmetros utilizados acham-se na Tabe 1a 1 .

A cada valor de pressão de acetileno ou de ar testado, o instrumento era zerado com a prova em branco (etanol absoluto).

o tempo de leitura para cada padrão foi de 10-20 s: a partir do momento da aspiração. Para soluções padrão em água o mesmo proce dimento foi adotado, apōs se fazer uma var redura inicial dos fluxos de ar e de aceti leno, em torno dos valores 18,5 e $3,7 \ell \cdot \mathrm{min}^{-1}$, respectivamente. A taxa de aspiração foi mantida em $8 \mathrm{~m} \ell \cdot \mathrm{min}^{-1}$. As concentrações das soluções foram: cálcio, ferro, cobre, cromo e manganês $-2,0 \mu g \cdot m \ell^{-1}$, zinco e potássio $-1,0 \mu \mathrm{g} \cdot \mathrm{m} \ell^{-1}$, sódio e magnēsio-0,5 $\mu \mathrm{g} \cdot \mathrm{m} \ell^{-1}$.

3.2.4. Estudo da Posição Relativa do Queimador

De acordo com EINTA (1965), a distribuição dos átomos no estado fundamental na chama não é homogênea. Dessa maneira, diferentes alturas de observação na chama resultarão em diferentes absorbâncias pa ra um determinado metal. Segundo RANN e HAMBLY (1965), a altura da re 
gião de máxima absorção na chama è dependente da taxa de formação e deple ção dos átomos, uma vez que a vida do átomo no estado fundamental depen de do ambiente através do qual ele caminha. o tipo de combustível e a razão combustível/comburente são os principais fatores que controlam es te ambiente. Por outro lado, ROBINSON (1960) ressalta que a posição cor reta da chama deve ser otimizada para cada solvente, uma vez que diver sos solventes liberam átomos metálicos a diferentes velocidades em altu ras variáveis da chama. Assim, para um mesmo elemento, dependendo da es tequiometria da chama, diferentes perfis verticais de distribuição atômi ca são normalmente obtidos.

No presente trabalho, estabelecidas as quantidades relati vas dos gases componentes da chama que forneceram a máxima absorbância, foram determinadas curvas típicas para cada elemento, ou seja, perfis de distribuição vertical.

Para tanto, utilizaram-se as mesmas soluções padrão descritas no item 3.2.3., sendo man tidas constantes as outras variāveis, tanto para soluções alcoōlicas como para aquosas. Desse modo, o gradiente de distribuição dos elementos atomizados, em chama de ar-aceti leno, foi determinado através de leituras de absorbância, tomadas a cada 1,25 man do per curso vertical da chama, a partir da base do queimador. Um alinhamento horizontal da chama em relação ao feixe ótico foi realiza 
do na altura de máxima absorbância do pér fil vertical.

3.2.5. Es tudo da Influência do Grau Alcoōlico das Amostras

Verifica-se pela revisão da literatura, tanto na ārea de bebidas alcoólicas como na de solventes orgânicos, a preocupação dos au tores em manter sempre o mesmo grau alcoólico, após estabelecida a gra duação específica para cada análise. Isto se deve ao fato de que a pre sença de solventes orgânicos, em diferentes concentrações, provoca alte rações diversas sobre a sensibilidade, não sendo possỉvel, portanto, es tabelecer comparações precisas entre as amostras.

Una vez que solventes orgânicos são miscíveis com ägua em proporções variadas e que uma pequena quantidade de água pode alterar con sideravelmente as características de combustão de tais soluções, precau ções devem ser tomadas para manter constante o conteúdo de água da amos tra, padrões e brancos para evitar erros nas medições (WELZ, 1976). A presença de água no solvente orgânico pode ocasionar mudanças na eficiên cia de nebulização, fato comprovado experimentalmente por WINEFORDNER et alii (1963). Ā medida que se diminuia a quantidade de água nas misturas metanol-ägua, aumentava-se a eficiência de introdução da amostra na cha ma.

Em 1973, LEMONDS e MCCLELLAN evidenciaram que a sensibili dade da absorção atômica é influenciada pelas propriedades físicas dos solventes, tais como viscosidade, ponto de ebulição, densidade e tensão superficial. Ressaltam ainda que a viscosidade é a propriedade física 
mais importante na anālise de materiais orgānicos por AAS, pois controla a taxa de aspiração.

Segundo especificações técnicas constantes do Ato no 14/80 do MIC - Instituto do Açúcar e do Ālcool, o álcool etílico estā classifi cado nos seguintes tipos, com teor alcoólico obtido a $20^{\circ} \mathrm{C}$ e expresso em INPM :

$$
\begin{aligned}
& \text { á1cool etílico anidro }-\min 99,30 \\
& \text { á1cool etílico hidratado }-92,50 \text { a } 93,70 \\
& \text { á1cool etílico refinado - min } 94,20
\end{aligned}
$$

Por essas razões, um estudo da influência da variação do grau alcoōlico sobre a absorbân cia foi realizado, conforme o procedimento a seguir.

Para cada elemento estudado, preparou-se uma série de dez soluções com grau alcoōlico vạ riando na faixa de 90,00 a $99,80 \%$ v/v e com concentração fixa do elemento. Foi escolhi da a concentração de $1,0 \mu g \cdot m \ell^{-1}$ para o fex ro, cálcio, cromo, cobre, manganês, zinco e potássio, $0,5 \mu \mathrm{g} \cdot \mathrm{m} \ell^{-1}$ para o sódio e 0,1 $\mu g \cdot m \ell^{-1}$ para o magnésio, de acordo com a sensibilidade de cada elemento. Assim, a um balão volumétrico de $100 \mathrm{~m} \ell$, a dicionaram-se $10 \mathrm{~m} \ell$ de uma solução padrão 
dez vezes mais concentrada em cada elemento estudado. Em seguida, foram adicionados de 0,00 a 10,00 ml de água, com incrementos de $1,00 \mathrm{~m} \ell$, sendo o volume completado lentamen te com etanol.

Seguindo o mesmo procedimento, uma série de provas em branco foi preparada, com grau a coólico correspondente às séries dos nove elementos estudados. Os teores alcoölicos de todas as soluções pa drão e provas em branco foram determinados em densỉmetro.

3.2.6. Caracterîsticas Analíticas: precisão, exatidão, limite de deteção e sensibilidade

A avaliação das características analíticas do método estü dado segue as normas preconizadas pela INTERNATIONAL UNION OF PURE AND APPLIED CHEMISTRY (IUPAC, 1978), que afirmam: os méritos de um procedi mento analítico podem ser caracterizados pelo seu limite de deteção, pre cisão e exatidão.

\subsubsection{Precisão}

A incerteza no valor de uma medida, $x$, ou a correspondente incerteza na estimativa da concentração, $c$, ou quantidade, $q$, é repre 
sentada pela precisão, a qual é convenientemente expressa pelo termo des vio padrão, $s$, ou pelo desvio padrão relativo $s_{r}=s / \bar{x}$ onde

$$
s=\left[\sum_{j=1}^{n}\left(x_{j}-\bar{x}\right)^{2} /(n-1)\right]^{1 / 2}
$$

é o desvio padrão de uma medida $x$ repetida $n$ vezes, e

$$
\bar{x}=\sum_{j=1}^{n} x_{j} / n
$$

a média de $n$ medidas e $x_{j}$ una medição individual.

Estabelecidas as melhores condições de ope ração para cada elemento, foram realizadas 20 medidas de absorbância, integrando-se o sinal durante 10 segundos, para cada medida. Para se efetuar estas medidas, foram prepara das soluções padrão nas concentrações 0,1 e $1,0 \mu \mathrm{g} \cdot \mathrm{m} \ell^{-1}$ para ferro, cromo, manganês, cál cio, cobre e potássio, 0,05 e $0,5 \mu g \cdot m \ell^{-1}$ pa ra sódio e zinco e 0,02 e $0,2 \mu \mathrm{g} \cdot \mathrm{m} \ell^{-1}$ para magnésio.

\section{$3 \cdot 2 \cdot 6 \cdot 2$. Exatidão}

A exatidão mostra a concordância entre a concentração me dida e o valor real. 
Na falta de amostras de etanol com composi ção química certificada e de métodos reco mendados para a determinação dos metais em etano1, a exatidão do método proposto foi avaliada através de testes de recuperação. Algumas amostras de etanol foram previamen te selecionadas para a realização deste es tudo. Dessa forma, para cada elemento em questão, transferiram-se $10 \mathrm{~m} l$ de uma solu ção padrão, para balão volumétrico de 100 $m \ell$, de forma a permitir um aumento na con centração final do elemento, não superior a 3 vezes a concentração inicial da amostra, após ser completado o volume com a amostra selecionada. Em cada caso particular, ob servou-se a graduação alcoólica da amostra, antes e após a adição da solução padrão.

3.2.6.3. Limite de Deteção

0 limite de deteção, expresso como a concentração, $c_{L}$, ou a quantidade, $q_{L}$, é derivado da menor medida, $x_{L}$, que pode ser detetada com uma certeza razoável para um determinado procedimento analítico. 0 valor de $x_{L}$ é dado pela equação:

$$
x_{L}=\bar{x}_{b L}+k s_{b l}
$$


onde

$$
\begin{aligned}
& \bar{x}_{b l} \text { é a média das medidas da prova em branco, } \\
& s_{b l} \text { é o desvio padrão das medidas da prova em branco e } \\
& k \quad \text { é um fator numérico escolhido de acordo com o nível de confian } \\
& \text { ça desejado. Um valor de } 3 \text { para } k \text { é recomendado, pois para es } \\
& \text { te valor aplica-se um nível de confiança de } 99,7 \% .
\end{aligned}
$$

$$
\begin{aligned}
& \text { Seguindo-se estas recomendações, foram rea } \\
& \text { lizadas } 20 \text { leituras da prova em branco (eta } \\
& \text { nol absoluto), integrando-se o sinal de ca } \\
& \text { da medida durante } 10 \text { segundos, empregando as } \\
& \text { condições otimizadas para cada elemento. }
\end{aligned}
$$

\subsubsection{Sensibilidade}

A sensibilidade, $S_{i}$, para o elemento $i$ é definida como a inclinação da curva de padronização. O método é tido como sensível se una pequena variação na concentração, $c$, ou quantidade, $q$, ocasiona uma grande variação na medida, $x$, ou seja, quando a derivada $\mathrm{d} x / \mathrm{d} c$ ou $\mathrm{d} x / \mathrm{d} q$ é grande.

Entretanto, o termo sensibilidade tem sido frequentemente mal utilizado em AAS para denotar a concentração necessária para causar $1 \%$ de absorção ou 0,0044 unidades de absorbância. Desse modo, o termo concentração característica foi recomendado para este valor particular. 


\section{RESULTADOS E DISCUSSÃO}

\subsection{Es tudo da Razão Acetịleno-Ar}

De acordo com o procedimento descrito em 3.2.3., foram ob tidas as curvas de absorbância em função da razão acetileno-ar para os nove elementos em estudo. Verificou-se um comportamento característico de cada metal, resultando em diferentes perfis de absorbância (Figuras 1 e 2l, obtidos entre 5 a 7,5 mm da superfície do queimador, com exceção do cromo, que nesta altura não apresentou sinal mensurável. Observou-se que para os elementos ferro, sódio, cobre e zinco, a mesma razão acetile no-ar propiciou a máxima absorbância. Cálcio, magnésio, potássio e man ganês apresentaram o melhor valor sinal-ruído em razões acetileno-ar mais reduzidas, ao passo que para o cromo, uma razão mais alta foi necessária. Deve-se ressaltar que o fluxo de combustível foi escolhido, considerando não apenas o ganho da sensibilidade, mas principalmente a precisão das me dições, ou seja, quando uma pequena variação no fluxo de acetileno produ zisse uma grande variação na absorbância.

Comparando-se os perfis de absorbância obtidos para eta nol e ăgua, nota-se que as mesmas tendências existiram para os dois sol 


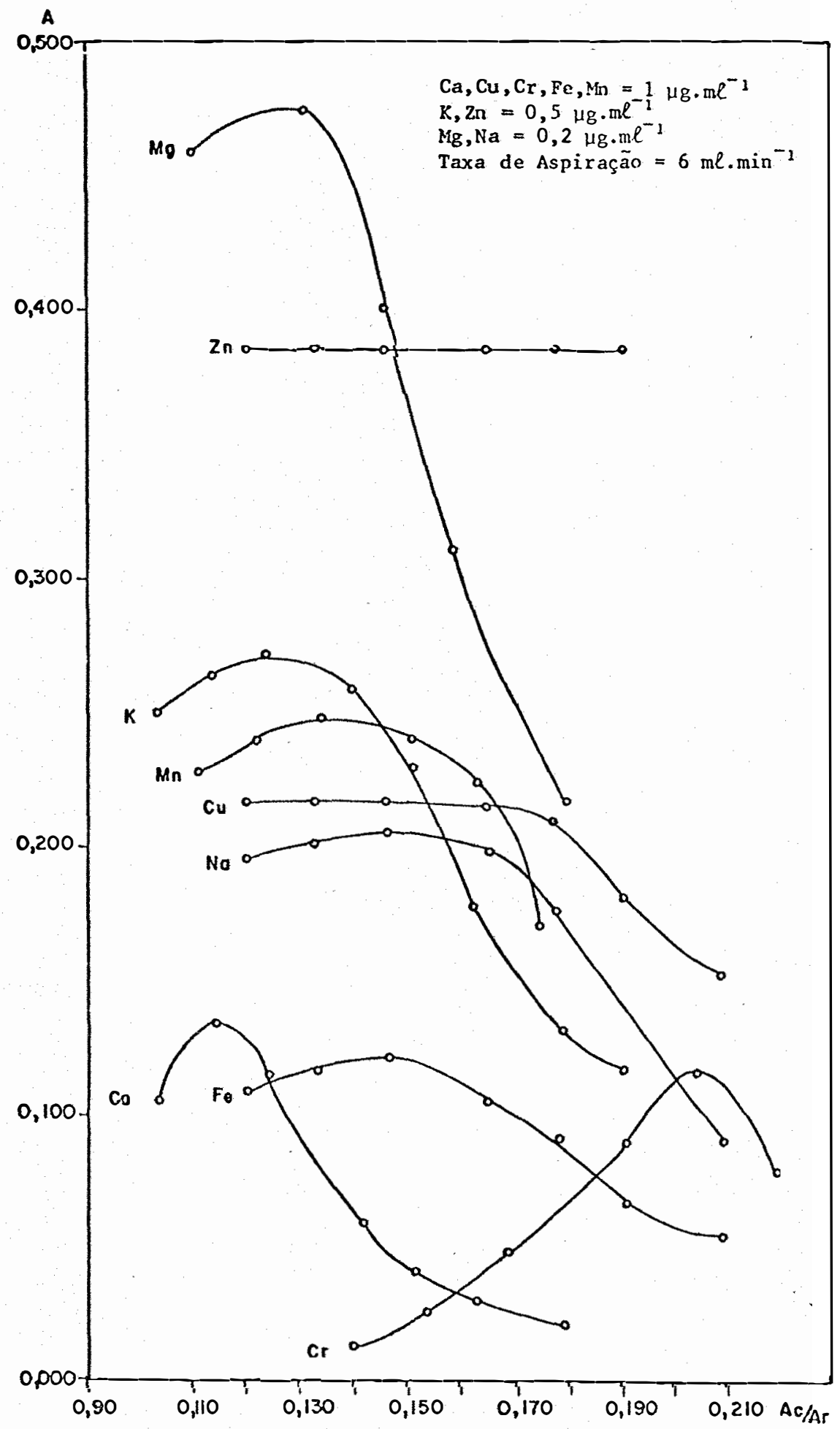

.38 . 


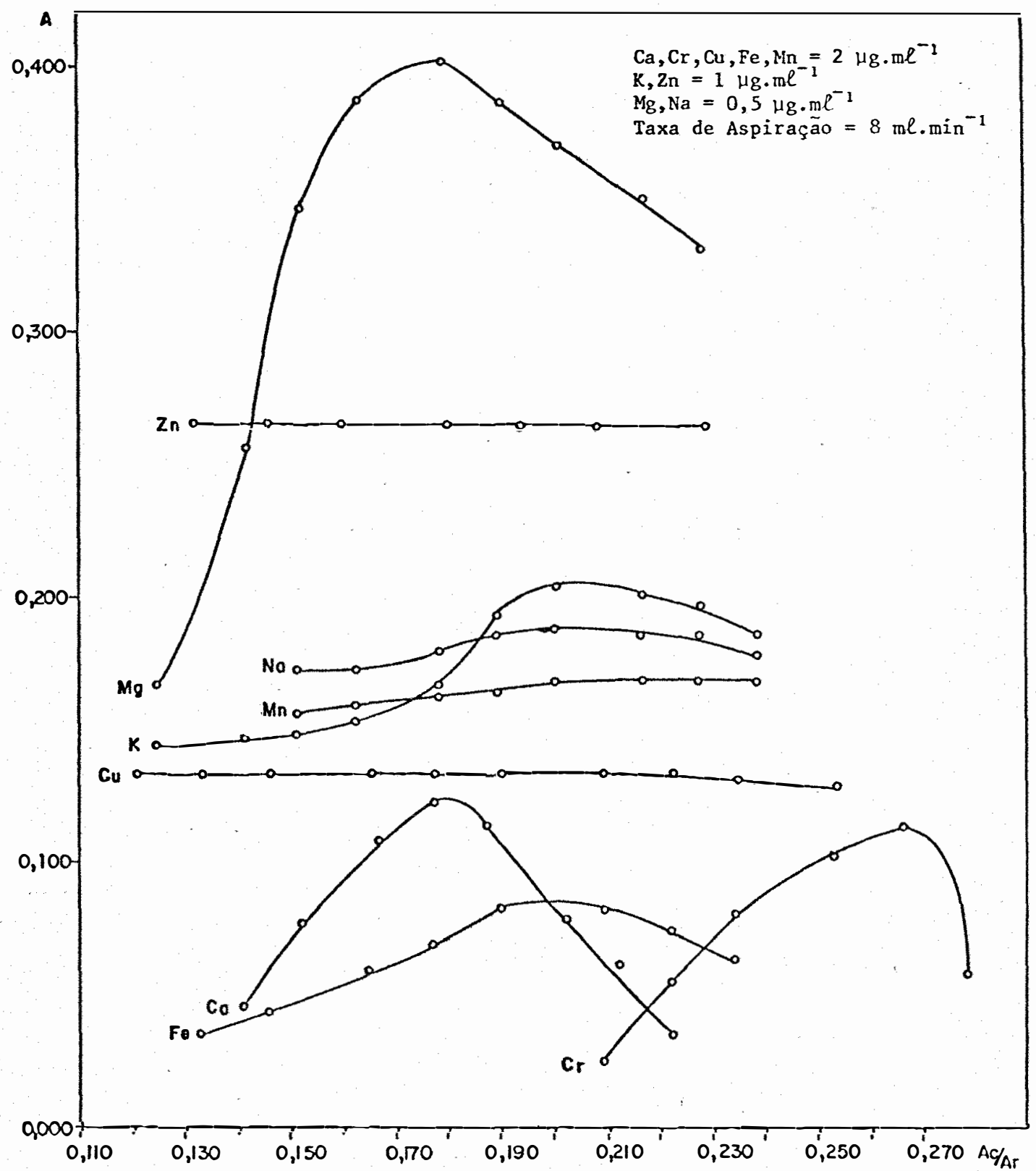

FIGURA 2. Curvas de absorbância dos elementos em ägua em função da razão acetileno-ar. 0 fluxo de ar e a altura do queimador foram fi xados nos valores dados: na Tabela 2 para cada elemento. 
ventes, diferenciando apenas na razão acetileno-ar empregada. Assim, a razão acetileno-ar ajustada nas condições ótimas para a determinação de metais em etanol foi sempre inferior àquela para o mesmo elemento em solução aquosa (Tabela 2). Neste particular, deve-se considerar que sen do o etanol um combustível, ele vai substituir parcialmente o acetileno na composição da chama. Então, para um cálculo correto da estequiometria da chama, deve-se levar em conta este combustível adicional.

\section{Cálcio}

No estudo da melhor razão acetileno-ar, isto é, aquela que proporcionasse a maior absorbância, verificou-se que no caso do cá1 cio, se trata de uma função convexa bastante aguda, com pico de máximo em torno de 0,114, decrescendo rapidamente em ambos os ramos da curva. Desse modo, os fluxos dos gases devem ser cuidadosamente ajustados, pois ao se aumentar o fluxo de acetileno em 0,2 e $0,4 \ell \cdot \mathrm{min}^{-1}$ acima do valor - ótimo, ob tém-se um decréscimo de absorbância aproximado de $18 \%$ e 57\%, res pectivamente. SLAVIN et alii (1963) e RANN e HAMBLY (1965) observaram o mesmo efeit to da razão acetileno-ar na absorção do cálcio. Estes auto res verificaram que à medida que a razão acetileno-ar era aumentada, o pico de absorção se deslocava para um ponto mais alto na chama. Todavia, a forma da curva não era significativamente alterada e o valor máximo de absorção permaneceu praticamente o mesmo para as diversas relações estu dadas. No entanto, THOMPSON e REYNOLDS (1978) afirmam que o cálcio pode apresentar picos de absorção máxima em duas razões acetileno-ar distin tas, ou seja, em chamas redutora e oxidante. Nesta ültima, porém, obtém -se a máxima sensibilidade, confirmando os resultados do presente traba 


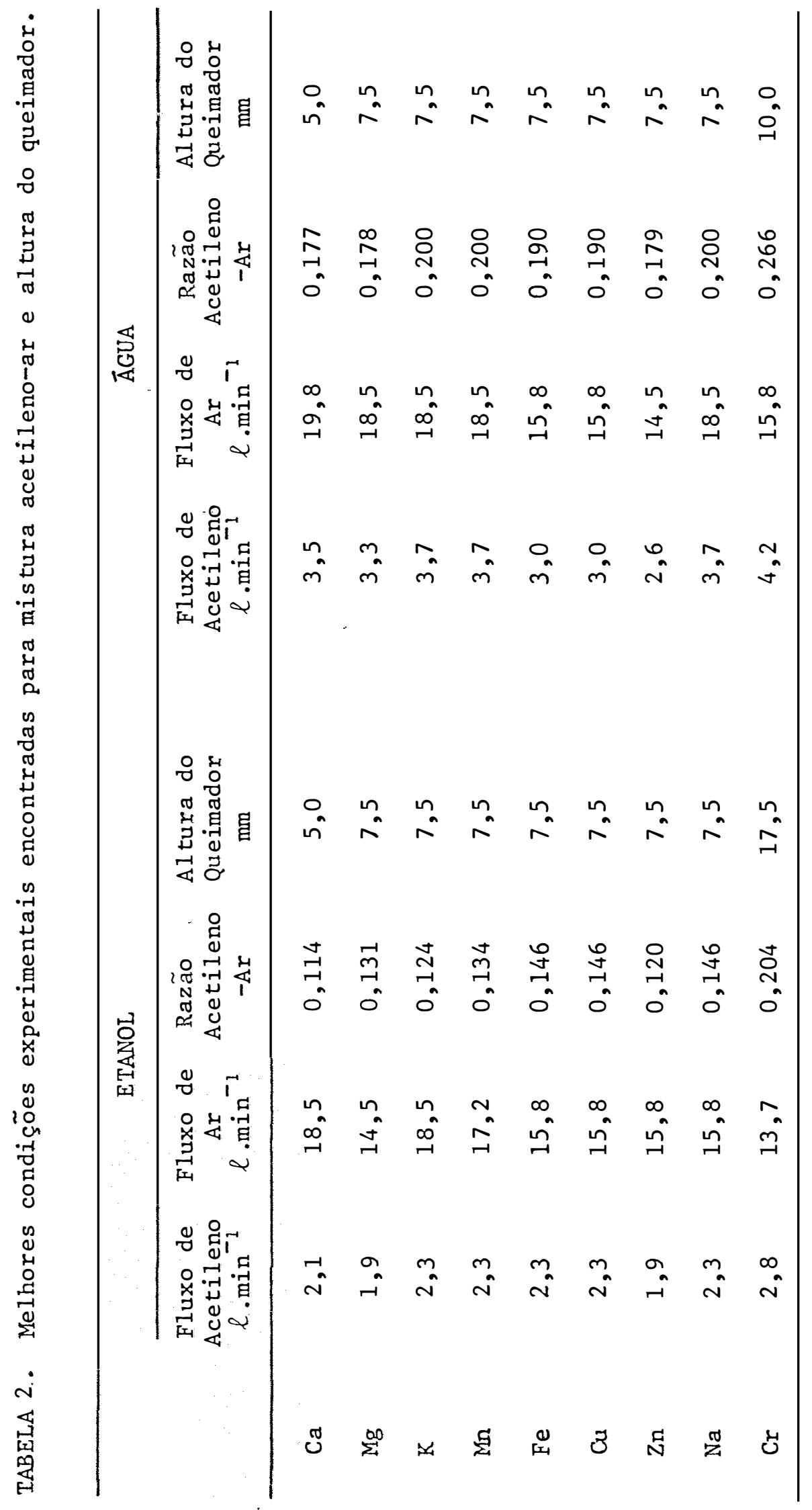


1ho.

\section{Magnésio}

A melhor razão acetileno-ar encontrada para este elemen to foi 0,131 , observando-se um rápido decréscimo nos valores de absorbân cia, alèm deste valor. Assim como para o cálcio, verificou-se que as con dições de máxima absorbância são bem definidas, resultando que pequenas variações nos fluxos dos gases podem ocasionar desvios consideráveis nos valores de absorbância, comprometendo a sensibilidade da determinação. Para este elemento, THOMPSON e REYNOLDS (1978) recomendam uma chama rela tivamente mais rica em combustivel.

\section{Potássio}

A razão acetileno-ar ótima para potássio foi encontrada em 0,124 , não sendo, entretanto, um valor tão crítico quanto para o cá1 cio e magnésio, pois uma variação de $\pm 0,4 l$ de acetileno em torno do flu xo escolhido ocasionou um decréscimo aproximado de $8 \%$ na absorbância. Segundo CHRISTIAN e EELDMAN (1970), uma chama oxidante è satisfatória pa ra a determinação de potássio, mas uma chama levemente redutora propor ciona maior sensibilidade face à redução da porcentagem de ionização.

\section{Manganês}

o pico máximo de absorbância foi encontrado com uma ra zão de 0,134, aproximadamente igual à do magnésio, porêm com um perfil pouco pronunciado, comparando-se àqueles obtidos por FELDMAN et alii (1967). 


\section{Ferro}

Para este elemento, observou-se uma variação menos acen tuada da absorbância com os fluxos dos gases, verificando-se uma razão ótima em 0,146. Entretanto, a sensibilidade da determinação torna-se ra zoavelmente comprometida em chamas mais ricas em acetileno, pois obtém-se uma perda de $19 \%$ no sinal, ao se aumentar 0,4 l.min ${ }^{-1}$ no fluxo de aceti leno estabelecido para a māxima absorbância.

Cobre

Verificou-se que a absorbância māxima é obtida para uma série de razões acetileno-ar, com o sinal apresentando uma queda signi ficativa a partir de uma razão 0,170 . 0 perfil sugere que o mesmo nú mero de átomos neutros de cobre existe na chama para vārias razões com bustíve1-comburente, estando de acordo com as observações de ALLAN (1961). Este autor observou que nenhum aumento na absorção do cobre é obtido ao se utilizar uma chama rica em combustíve1, pois o cobre existe na chama totalmente no estado atômico.

\section{Zinco}

Um comportamento diferente dos outros elementos testados foi observado para zinco, ou seja, a absorbância permaneceu inalterada em todas as razões acetileno-ar. Supõe-se, então, que todo o zinco que alcança a chama é levado ao estado fundamental, independentemente da com posição da chama, fato tambēm confirmado por ALLAN (1961). No entanto, inümeros autores afirmam que o zinco é mais sensîvel em uma chama oxidan te (CHRISTIAN e FELDMAN, 1970; PINTA, 1935, entre outros). Conforme men 
cionado em 3.2.2., a chama ar-acetileno absorve apreciavelmente abaixo de $230 \mathrm{~nm}$ e a linha $213,9 \mathrm{~nm}$ do zinco está compreendida nesta região es pectral. Assim, apesar do valor de absorbância ter permanecido o mesmo para todas as razões usadas, o ruído da chama foi bastante instável com altos fluxos de acetileno. Por este motivo, escolheu-se o menor fluxo de acetileno, correspondendo a $1,9 \ell \cdot \mathrm{min}^{-1}$, resultando numa razão de 0,120. CHRISTIAN e FELDMAN (1970) reportam que um aumento de sensibili dade foi observado ao se empregar pressões de ar e acetileno inferiores às recomendadas pelos manuais do aparelho.

\section{. Södio}

0 perfil de absorbância para sódio mostrou que este ele mento é determinado com maior sensibilidade em chamas menos ricas em ace tileno. Assim, uma variação de $\pm 0,4 \ell$ em torno do valor ótimo de aceti leno ocasionou decréscimos de $5 \%$ para a razão mais oxidante e $9 \%$ para a mais redutora.

\section{Cromo}

De todos os nove elementos estudados, o cromo foi aquele que se diferenciou dos demais em composição e altura da chama. Mantendo uma chama oxidante, nenhum sinal foi verificado em qualquer altura de ob servação. Desse modo, uma razão acetileno-ar mais alta foi necessāria, propiciando uma chama redutora, de aspecto amarelado e opaco. Observa-se pelo perfil de absorbância que o fluxo de acetileno é um parâmetro de grande importância na determinação de cromo, juntamente com a altura da chama. Do mesmo modo, FELDMAN e PURDY (1965) mostraram que as condi 
ções da chama são extremamente críticas na obtenção da máxima sensibili dade para este elemento. A altura do queimador foi especialmente críti ca e uma chama altamente redutora apresentou os melhores resultados, uma vez que o cromo tende a formar óxidos refratärios na chama.

\subsection{Estudo da Posição Rerativa do Queimador}

Os perfis de absorbância dos nove elementos atomizados em chama de ar-acetileno, de composição definida para cada elemento, foram obtidos em 27,5 mm de percurso vertical na chama, seguindo o procedimento detalhado em 3.2.4. (Figuras 3 e 4). Ficou evidente que os diferentes elementos estudados apresentam comportamentos peculiares na chama e que a distribuição atômica a uma dada razão comburente-combustível è função da posição na chama.

Com exceção do cromo, que se atomizou mais em chama altą mente redutora, os outros elementos tiveram seu pico máximo de absorbân cia em chamas estequiométricas a oxidantes. Nestas condições, a altura de máxima concentração dos átomos no estado fundamental foi observada $\underline{i}$ mediatamente acima do cone da chama, ou seja, de 5 a $7,5 \mathrm{~mm}$ da superfície do queimador. Os elementos magnésio, potássio, cálcio e zinco apresenta ram perfis de distribuição atômica aproximadamente iguais. A partir da altura de observação ótima, um rápido decréscimo na absorbância foi cons tatado, indicando que o número de átomos no estado fundamental diminuiu com a altura da chama. A distribuição dos átomos de ferro, cobre, sódio e manganês foi mais gradual, enquanto que a do zinco foi intermediária. A àltura de observação para o cromo è um parâmetro de importância e a concentração atômica passa por um pico máximo bem definido. 


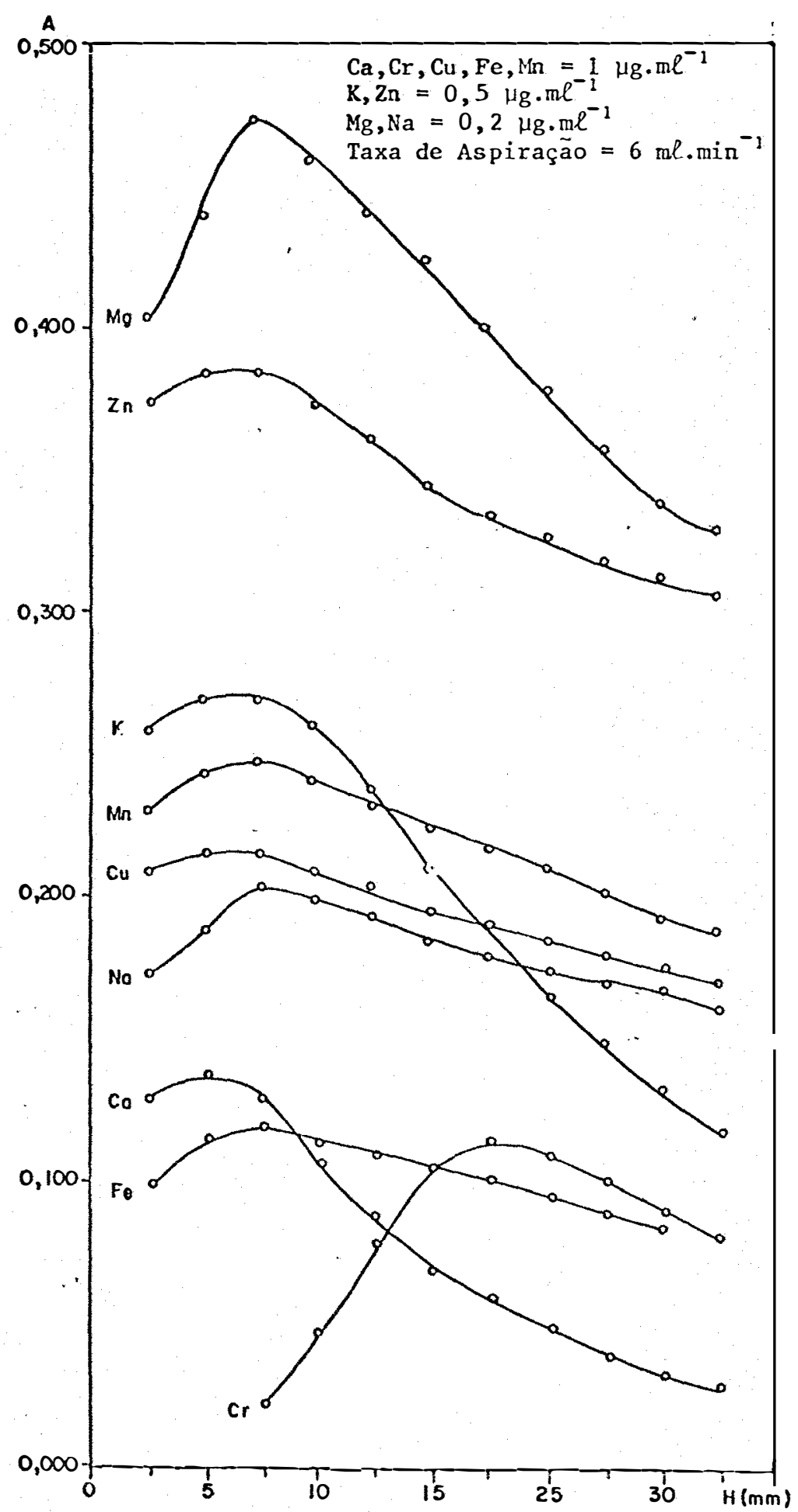

.46. 


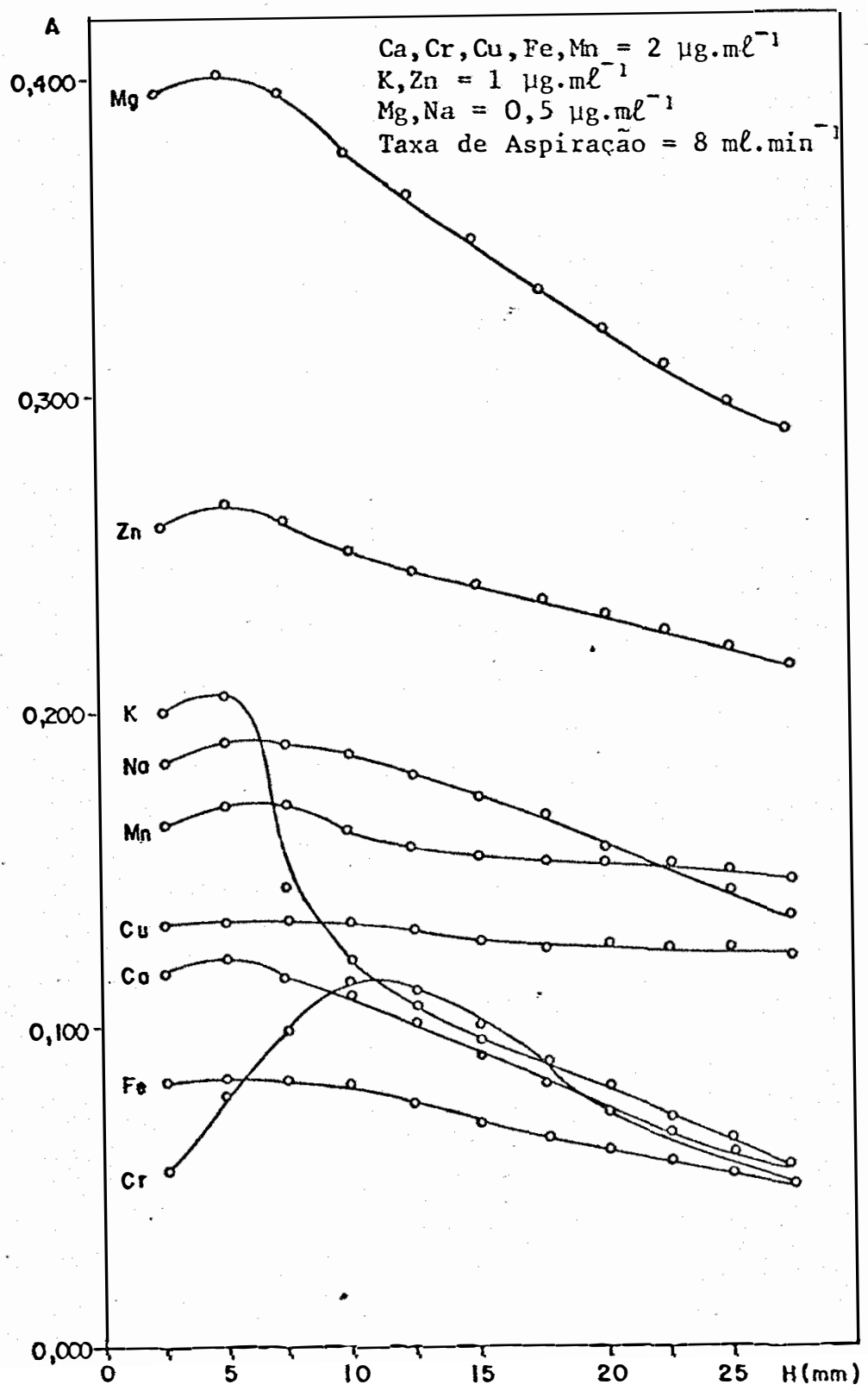

FIGURA 4. Perfil de absorbância dos elementos em água em relação à altu ra (H) do queimador. Os fluxos de acetileno e de ar para ca da elemento são dados na Tabela 2. 
Os resultados sugerem que o räpido decrēscimo na concen tração de átomos no estado fundamental com a altura de observação na cha ma pode ser explicado por:

a) evaporação mais râpida do solvente orgânico nos prime ros milímetros de percurso na chama, fato evidenciado experimentalmente por GIBSON et alii (1963). Este au tor verificou que o aerosol de acetona evaporava rap $\underline{i}$ damente e nenhuma gotícula era encontrada além de $10 \mathrm{~mm}$ do topo do queimador. No caso de solvente aquoso, o mesmo estudo revelou que o aerosol era claramente visí vel através do volume todo da chama, sendo óbvio que algumas gotas atravessavam a chama sem serem completa mente evaporadas;

b) local de máxima temperatura, onde a maior concentração atômica é encontrada para a maioria das distribuições em chamas estequiométricas e oxidantes. Tanto GIBSON et alii (1963) como RANN e HAMBLY (1965) observaram es .te efeito na região próxima ao queimador, entre 0 e 10 $\mathrm{mm}$, para este tipo de chama. Os primeiros autores fi zeram ainda uma observação bastante interessante, quan to ao perfil de temperatura estabelecido em $45 \mathrm{~mm}$ do percurso vertical na chama, para solventes orgânicos e aquosos. Verificaram que existe uma determinada altu ra, na qual a temperatura da chama é insensível às mu danças nas razões combustíve1-comburente, pois os di 
versos perfis de temperatura se cruzam em um ponto, in dependente dos fluxos dos gases. Para solventes orgâa nicos, esta altura está situada mais próxima do queima dor $(20 \mathrm{~mm})$ do que para a água $(30 \mathrm{~mm})$;

c) expansão dos gases da chama com o ar atmosférico, resu1 tando numa diluição da concentração atômica. Uma vez que sódio não forma compostos na chama, GIBSON et alii (1963) mostraram que o decréscimo na concentração de átomos no estado fundamental com a altura era devido à diluição dos gases da chama. Tal estudo foi realizado através da integração da absorbância em diversas alturas da chama, verificando-se um aumento linear das ab sorbâncias integradas até $20 \mathrm{~mm}$, provavelmente devido à evaporação do solvente e decomposição dos sais sóli dos de sódio. Para o solvente àgua, cuja evaporação é mais lenta e requer maior energia, o valor máximo do perfil atômico é resultante de dois processos competi tivos, a evaporação tendendo a aumentar a população atômica com a altura e a diluição da chama, levando a um decréscimo na concentração de ätomos por unidade de volume.

Ainda com relação à temperatura da chama, deve-se obser var que a combustão de solventes orgânicos, ao contrārio da àgua, e uma reação exotérmica, não ocasionando, portanto, alterações significativas na temperatura ao se dessolvatar o aerosol entrante na chama. Este efei 
to pode explicar também porque uma população maior de átomos é encontrạ da logo nos primeiros milímetros de percurso, ou seja, assim que as gotí culas do aerosol penetram na chama, o etanol entra em combustão instânta nea, liberando mais rapidamente o átomo metálico. Pode-se considerar, en tão, que a posição da chama foi otimizada para a combustão completa do etanol, em cada caso particular, liberando apenas os átomos metälicos e os produtos da combustão, conforme as afirmativas de ROBINSON (1960).

\subsection{Es tudo da Influência do Grau Alcoōlico das Amostras}

Seguindo o procedimento detalhado em 3.2.5., foramobtidas curvas de correlação entre grau alcoólico e absorbância para os nove ele mentos estudados. Em todos os casos, observou-se um razoável decréscimo na absorbância ao se diminuir o grau alcoólico dos padrões de 99,8 a $90,0 \% \mathrm{v} / \mathrm{v}$, possivelmente devido às alterações nas propriedades físicas das soluções.

Segundo ALMEIDA (1952), a viscosidade das misturas hidro alcoólicas é crescente de 0 a $45 \%$ de álcool em volume, decrescendo em se guida. MONICK (1968) apresenta a densidade e a viscosidade de misturas etano1-ägua de 0 a $100 \% \mathrm{v} / \mathrm{v}$, a $25^{\circ} \mathrm{C}$. Observa-se que de 93,25 a $100 \% \mathrm{v} / \mathrm{v}$, a viscosidade decresce de 1,42 a 1,10 cps e a densidade de 0,8136 a $0,7851 \mathrm{~g} \cdot \mathrm{cm}^{-3}$. Da mesma forma, a tensão superficial e o ponto de ebuli ção também decrescem com o aumento do grau alcoōlico. Ao se diminuir a viscosidade, o tempo necessário para aspirar um dado volume também dimi nui e assim, o volume de solução que alcança a chama torna-se maior na unidade de tempo. Desse modo, a concentração do ion metálico presente na 
chama aumenta com a diminuição da viscosidade ou, em outras palavras, com o aumento do grau alcoólico na faixa de 93,5 a $100 \% \mathrm{v} / \mathrm{v}$.

A tensão superficial dos 1íquidos exerce influência no ta manho médio das gotículas. $\bar{A}$ medida que a tensão superficial diminui, as formas coesivas entre as moléculas são reduzìdas, favorecendo a formação de gotículas de menor tamanho. Assim, um aerosol mais fino é produzido, com maiores probabilidades de alcançar a chama.

0 ponto de ebulição das soluções altera diretamente a ta xa de evaporação das gotículas formadas. Solventes com baixo ponto de ebulição evaporam mais rapidamente, liberando mais facilmente a partícu la sólida a ser vaporizada. Dessa maneira, ao se diminuir o ponto de ebu lição, aumenta-se a eficiência do processo de liberação de átomos metāli cos na chama.

Pode-se concluir, então, que soluções etanólicas de maior grau alcoólico, ou seja, com menores tensão superficial, viscosidade, den sidade e ponto de ebulição concorrem para um aumento no nümero de átomos no estado fundamental na chama e, consequentemente, para um aumento na sensibilidade. Soluções com menor tensão superficial produzem gotículas diminutas resultando, portanto, em uma grande superfície exposta a evapo ração. Se o solvente tem baixo ponto de ebulição, a evaporação se proces sa rapidamente, produzindo partículas dessolvatadas em uma posição mais haixa da chama, com um tempo de residência relativamente maior no traje to ütîl da chama. Ainda mais, quanto menor a presença de água na mistü ra, maior a temperatura da chama, ocasionando mais rápida evaporação e 
vaporização do solvente e do soluto, respectivamente.

Face às considerações teóricas anteriormente discutidas, um ajuste das condições da chama deveria ser feito para cada teor alcoó lico em particular, o que tornaria pouco prático o método, em virtude da grande variação dos graus alcoólicos das amostras. Além disso, devido à inviabilidade de se preparar curvas de padronização de graduação corres pondente a cada amostra, procurou-se estabelecer uma curva única de cor reção para grau alcoólico para todos os elementos. Entretanto, como po de ser verificado pela Tabela 3, curvas com diferentes inclinações foram encontradas para cada elemento. Disso resulta que existe uma variação para cada sistema metal-solvente, ou seja, a mesma mistura etanol-água vai exercer influências específicas em cada elemento. Assim, o efeito de concentrações crescentes de āgua na mistura etanólica sobre a absorbân cia não pode ser atribuído unicamente às mudanças nas propriedades físi cas citadas, pois ao se fixar uma determinada concentração dos solventes etanol e āgua, o efeito foi quantitativamente diferente de um elemento a outro, aliās confirmado também por LOCKYER et alii (1961).

Analisando-se os coeficientes angulares das equações de re gressão obtidas (Tabela 3), pode-se considerar que os elementos zinco e manganês sofrem a mesma influência com relação ao grau alcoólico. Já o magnésio, cobre, potássio e ferro podem ser agrupados em um segundo com portamento. 0 sódio faria parte de um terceiro grupo, enquanto que cā1 cio e cromo seriam reunidos em un quarto grupo. As razões para estes com portamentos diversos não estão bem evidenciadas. Devido à presença de dois combustíveis na chrama, o acetileno e o etanol, uma quantidade razoá 
vel de radicais de carbono é encontrada na chama, conferindo-1he um carâa ter redutor. Assim, a pressão parcial do átomo de oxigênio em tal ambi ente é muito pequena e limitada pela dissociação térmica do oxigênio mo lecular. Dessa forma, ambos (o metal e o carbono) competem pelo oxigênio da chama, e a reação $C+0 \rightarrow C 0$ é preferencial em relação à $M+0 \rightarrow$ MO. No caso dos elementos que tendem a formar óxidos refratários na chama, as reações que produzem átomos no estado fundamental são dissociações térmi cas dos óxidos metálicos formados: (MO $¥ \mathrm{M}+0$ ). 0 carbono reagindo com o oxigênio, numa reação altamente exotérmica, desloca o equilíbrio da rea ção, da esquerda para a direita, formando mais átomos no estado fundamen tal CCHAKRABARTI e SINGHAL, 1969l. Os resultados obtidos para cálcio e cromo parecem concordar com esta teoria, pois ao se substituir gradativa mente o etanol dos padrões por água, verificou-se uma brusca diminuição da absorbância. Por exemplo, ao se passar de 99,8\% a 94,8\%, perdeu-se aproximadamente $29 \%$ do sinal para cálcio e $24 \%$ para o cromo.

Deve-se ressaltar que as equações de regressão foram obti das, fixando-se uma concentração única para cada elemento. Entretanto,o efeito resultante da variação do grau alcoólico pode não ser o mesmo em qualquer concentração do elemento. Desse modo, sugere-se que um estudo mais detalhado seja realizado, utilizando-se padrões de diversas concen trações dos elementos com graus alcoólicos variāveis. Assim, uma equação geral por elemento poderá ser obtida, com a finalidade de se corrigir o valor de absorbância de uma amostra com um determinado grau alcoólico di ferente do anidro. Deve-se ressaltar que se existirem diferentes curvas para o mesmo elemento nas diversas concentrações, então, os grupos de 
TABELA 3. Parâmetros da correlação linear entre o logaritmo natural da absorbância ( $\ln A$ ) e o grau alcoólico (GL) com condições experimentais de razão de gases e altura do queimador dadas na Ta bela 2 .

\begin{tabular}{ccccc}
\hline Elemento & $\begin{array}{c}\text { Concentração } \\
\mu g \cdot m \ell^{-}\end{array}$ & b & a & $\mathrm{r}^{2}$ \\
\hline $\mathrm{Mn}$ & 1 & 0,01607 & $-3,05955$ & 0,68251 \\
$\mathrm{Zn}$ & 1 & 0,01900 & $-2,15811$ & 0,98802 \\
$\mathrm{Mg}$ & 0,1 & 0,02559 & $-4,01682$ & 0,98880 \\
$\mathrm{Cu}$ & 1 & 0,02641 & $-4,16086$ & 0,98290 \\
$\mathrm{~K}$ & 1 & 0,02818 & $-3,38772$ & 0,90712 \\
$\mathrm{Fe}$ & 1 & 0,02913 & $-5,00407$ & 0,94100 \\
$\mathrm{Na}$ & 0,5 & 0,04577 & $-5,23281$ & 0,99756 \\
$\mathrm{Ca}$ & 1 & 0,06817 & $-8,77369$ & 0,99744 \\
$\mathrm{Cr}$ & 1 & 0,07676 & $-9,75938$ & 0,97595 \\
\hline
\end{tabular}

Equação de Regressão: $\ln A=a+b . G L$

$$
A=a \cdot e^{b \cdot G L}
$$

onde: $A=$ absorbância a qualquer nível de grau alcoōlico GL, entre 90,0 a $100,0 \%$ v /v. 
comportamento estabelecidos anteriormente não estão totalmente corretos, pois foram agrupadas equações obtidas a partir de concentrações diferen tes (magnēsio $0,1 \mu \mathrm{g} \cdot \mathrm{m} \ell^{-1}$, sōdio $0,5 \mu \mathrm{g} \cdot \mathrm{m} \ell^{-1}$ e os outros $1,0 \mu \mathrm{g} \cdot \mathrm{m} \ell^{-1}$ ).

\subsection{Caracteristicas Analiticas}

\subsubsection{Precisão}

A precisão das medições para cada elemento foi efetuada conforme detalhado em 3.2.6.1., em dois níveis de concentração. Observa -se pelos resultados apresentados na Tabela 4, um desvio padrão relativo menor que $0,5 \%$ para as concentrações maiores e menor que 4,5\% para as bai xas concentrações.

\subsubsection{Exatidão}

A exatidão do método proposto foi avaliada para cada ele mento, de acordo com o procedimento descrito em 3.2.6.2., e os resulta dos se encontram nas Tabelas 5 a 10.

Uma vez que em nenhuma das amostras de etanol foram encon trados níveis de cromo, cālcio e manganês, dentro da faixa analítica es tudada, os testes de recuperação não foram realizados para estes elemen tos. Entretanto, verifica-se que o método proposto è bastante exato, uma vez que as recuperações médias se situaram em torno de $100 \%$ para magnē sio, sódio, zinco, potássio, cobre e ferro. 


\subsubsection{Limite de Deteção}

As medidas das 20 provas em branco permaneceram constan tes em $0,0 a 1$ unidades de absorbância para todos os elementos. Desse mo do, com desvio padrão igual a 0,000 , a medida $x_{L}$, conforme item 3.2.6.3., é igual a 0,001. Assim, os limites de deteção foram extraídos das curvas de padronização obtidas para cada elemento (Tabelas 11 e 12) e se encon tram na Tabela 13. Pode-se observar que coincidentemente o limite de de teção foi igual à sensibilidade de determinação de cada elemento.

\subsubsection{Sensibilidade}

Por se tratar de um indicador digital, a menor grandeza observada corresponde a 0,001 unidades de absorbância, pois is to é o que significa uma variação de uma unidade no quarto dígito. Desta forma, a sensibilidade do sistema está limitada a este valor, e a incerteza da me dida estā no quarto algarismo significativo. Entretanto, fazendo-se uma série de medidas e tirando-se a média, é possível ganhar mais um algaris mo significativo, jogando-se a incerteza para o quinto dígito, porém is to não significa que a sensibilidade do aparelho foi aumentada. Uma vez definida a sensibilidade do instrumento em termos de absorbância, pode -se agora calcular a sensibilidade do método, em termos de concentração, para cada elemento estudado. Basta para isso, multiplicar-se o coefici ente angular (b) da reta de regressão da padronização pelo valor da sen sibilidade em absorbância. A Tabela 13 reúne os valores obtidos para as sensibilidades dos nove elementos estudados, em etanol e água. A Tabela 14 mostra os valores das concentrações características resultantes das 
curvas de padronização dos elementos nos dois solventes. Os valores ob servados por WELZ (19.76) e THOMPSON e REYNOLDS (19.78) foram apresentados para mostrar a concordância dos resultados do presente trabalho, quando se utilizou soluções aquosas. Estahelecendo-se uma comparação das sensi bilidades encontradas, observa-se que a sensibilidade da determinação dos nove elementos em etanol foi de duas a três vezes maior em relação àquela verificada para a água, ou seja,o fator de ganho é de 2 a 3 vezes. 
.58 .

TABEla 4. Precisão da análise expressa pelo desvio padrão relativo $\left(s_{p}\right)$, para 20 repetições e dois níveis de concentração. As condi ções experimentais de razão de gases e altura do queimador são dadas na Tabela 2.

\begin{tabular}{ccccc}
\hline Elemento & $\begin{array}{c}\text { Concentração } \\
\mu \mathrm{g} \cdot \mathrm{m} \ell^{-1}\end{array}$ & $s_{p}(\%)$ & $\begin{array}{c}\text { Concentração } \\
\mu \mathrm{g} \cdot \mathrm{m} \ell^{-1}\end{array}$ & $s_{p}(\%)$ \\
$\mathrm{Cu}$ & 0,1 & 2,99 & 1,0 & 0,41 \\
$\mathrm{Fe}$ & 0,1 & 3,99 & 1,0 & 0,43 \\
$\mathrm{~K}$ & 0,1 & 0,81 & 1,0 & 0,12 \\
$\mathrm{Cr}$ & 0,1 & 0,00 & 1,0 & 0,39 \\
$\mathrm{Ca}$ & 0,1 & 4,33 & 1,0 & 0,44 \\
$\mathrm{Mn}$ & 0,1 & 2,27 & 1,0 & 0,21 \\
$\mathrm{Na}$ & 0,05 & 1,04 & 0,5 & 0,11 \\
$\mathrm{Zn}$ & 0,05 & 2,12 & 0,5 & 0,34 \\
$\mathrm{Mg}$ & 0,02 & 1,27 & 0,2 & 0,39 \\
\hline
\end{tabular}


TABELA 5. Teste de recuperação de magnésio.

\begin{tabular}{|c|c|c|c|c|}
\hline \multirow{2}{*}{ Amostra } & \multicolumn{3}{|c|}{ Magnēsio ( $\mu g$ ) } & \multirow{2}{*}{$\begin{array}{c}\text { Recuperação } \\
\%\end{array}$} \\
\hline & $\begin{array}{l}\text { Originalmente } \\
\text { medido }\end{array}$ & Adicionado & Encontrado & \\
\hline \multirow[t]{2}{*}{2} & 0,28 & 0,25 & 0,50 & 94,34 \\
\hline & & 0,50 & 0,79 & 101,28 \\
\hline \multirow[t]{2}{*}{5} & 0,25 & 0,25 & 0,50 & 100,00 \\
\hline & & 0,50 & 0,75 & 100,00 \\
\hline \multirow[t]{2}{*}{18} & 0,20 & 0,10 & 0,30 & 100,00 \\
\hline & & 0,25 & 0,45 & 100,00 \\
\hline \multirow[t]{2}{*}{20} & 0,22 & 0,10 & 0,32 & 100,00 \\
\hline & & 0,25 & 0,45 & 95,74 \\
\hline \multirow[t]{2}{*}{23} & 0,38 & 0,25 & 0,65 & 103,17 \\
\hline & & 0,50 & 0,91 & 103,41 \\
\hline \multirow[t]{2}{*}{24} & 0,56 & 0,50 & 1,10 & 103,77 \\
\hline & & 1,00 & 1,62 & 103,84 \\
\hline$\overline{\mathrm{m}}$ & - & - & - & 100,46 \\
\hline
\end{tabular}


TABELA 6. Teste de recuperação de sódio.

\begin{tabular}{|c|c|c|c|c|}
\hline \multirow{2}{*}{ Amos tra } & \multicolumn{3}{|c|}{ Sódio $(\mu g)$} & \multirow{2}{*}{$\begin{array}{c}\text { Recuperação } \\
\%\end{array}$} \\
\hline & $\begin{array}{l}\text { Originalmente } \\
\text { medido }\end{array}$ & Adicionado & Encontrado & \\
\hline \multirow[t]{2}{*}{40} & 0,80 & 0,50 & 1,30 & 100,00 \\
\hline & 0,80 & 1,00 & 1,78 & 98,89 \\
\hline \multirow[t]{2}{*}{48} & 2,23 & 1,00 & 3,25 & 100,62 \\
\hline & 2,23 & 2,50 & 4,75 & 100,42 \\
\hline \multirow[t]{2}{*}{57} & 4,15 & 2,50 & 6,70 & 100,75 \\
\hline & 4,15 & 5,00 & 9,10 & 99,45 \\
\hline \multirow[t]{2}{*}{20} & 7,25 & 5,00 & 12,15 & 99,18 \\
\hline & 7,25 & 10,00 & 17,20 & 99,71 \\
\hline \multirow[t]{2}{*}{21} & 18,50 & 10,00 & 28,50 & 100,00 \\
\hline & 18,50 & 25,00 & 32,50 & 97,01 \\
\hline$\overline{\mathrm{m}}$ & - & - & - & 99,60 \\
\hline
\end{tabular}


TABELA 7. Teste de recuperação de zinco.

\begin{tabular}{|c|c|c|c|c|}
\hline \multirow{2}{*}{ Amostra } & \multicolumn{3}{|c|}{ Zinco $(\mu g)$} & \multirow{2}{*}{$\begin{array}{c}\text { Recuperação } \\
\%\end{array}$} \\
\hline & $\begin{array}{l}\text { Originalmente } \\
\text { medido }\end{array}$ & Adicionado & Encontrado & \\
\hline \multirow[t]{2}{*}{4} & 2,00 & 2,50 & 4,50 & 100,00 \\
\hline & & 5,00 & 6,88 & 98,29 \\
\hline \multirow[t]{2}{*}{10} & 1,03 & 1,00 & 1,88 & 92,61 \\
\hline & & 2,50 & 3,25 & 92,07 \\
\hline \multirow[t]{2}{*}{11} & 0,40 & 0,50 & 0,90 & 100,00 \\
\hline & & 1,00 & 1,38 & 98,57 \\
\hline \multirow[t]{2}{*}{17} & 1,84 & 1,00 & 2,79 & 98,24 \\
\hline & & 2,50 & 4,13 & 95,16 \\
\hline \multirow[t]{2}{*}{24} & 11,00 & 5,00 & 16,00 & 100,00 \\
\hline & & 10,00 & 21,25 & 101,19 \\
\hline$\overline{\mathrm{m}}$ & - & - & - & 97,61 \\
\hline
\end{tabular}


TABELA 8. Teste de recuperação de potássio.

\begin{tabular}{|c|c|c|c|c|}
\hline \multirow{2}{*}{ Amostra } & \multicolumn{3}{|c|}{ Potássio $(\mu g)$} & \multirow{2}{*}{$\begin{array}{c}\text { Recuperação } \\
\%\end{array}$} \\
\hline & $\begin{array}{l}\text { Originalmente } \\
\text { medido }\end{array}$ & Adicionado & Encontrado & \\
\hline \multirow[t]{2}{*}{43} & 3,60 & 2,50 & 6,00 & 98,36 \\
\hline & & 5,00 & 8,60 & 100,00 \\
\hline \multirow[t]{2}{*}{44} & 1,55 & 1,00 & 2,50 & 98,04 \\
\hline & & 2,50 & 4,10 & 101,23 \\
\hline \multirow[t]{2}{*}{54} & 1,15 & 1,00 & 2,20 & 102,33 \\
\hline & & 2,50 & 3,65 & 100,00 \\
\hline \multirow[t]{2}{*}{62} & 0,55 & 0,25 & 0,85 & 106,25 \\
\hline & & 0,50 & 1,05 & 100,00 \\
\hline \multirow[t]{2}{*}{65} & 1,25 & 1,00 & 2,25 & 100,00 \\
\hline & & 2,50 & 3,80 & 101,33 \\
\hline \multirow[t]{2}{*}{71} & 3,35 & 5,00 & 8,50 & 101,80 \\
\hline & & 10,00 & 13,75 & 103,00 \\
\hline$\overline{\mathrm{m}}$ & - & - & - & 101,03 \\
\hline
\end{tabular}


TABELA 9. Teste de recuperação de cobre.

\begin{tabular}{|c|c|c|c|c|}
\hline \multirow{2}{*}{ Amos tra } & \multicolumn{3}{|c|}{ Cobre $(\mu g)$} & \multirow{2}{*}{$\begin{array}{c}\text { Recuperação } \\
\%\end{array}$} \\
\hline & $\begin{array}{l}\text { Originalmente } \\
\text { medido }\end{array}$ & Adicionado & Encontrado & \\
\hline \multirow[t]{2}{*}{5} & 22,50 & 10,00 & 31,50 & 96,92 \\
\hline & & 25,00 & 43,56 & 91,70 \\
\hline \multirow[t]{2}{*}{18} & 6,88 & 5,00 & 12,75 & 107,32 \\
\hline & & 10,00 & 17,13 & 101,48 \\
\hline \multirow[t]{2}{*}{22} & 13,81 & 10,00 & 23,25 & 97,64 \\
\hline & & 25,00 & 38,25 & 98,55 \\
\hline \multirow[t]{2}{*}{23} & 0,75 & 0,50 & 1,25 & 100,00 \\
\hline & & 1,00 & 1,75 & 100,00 \\
\hline \multirow[t]{2}{*}{1175} & 1,88 & 1,00 & 2,88 & 100,00 \\
\hline & & 2,50 & 4,34 & 99,09 \\
\hline \multirow[t]{2}{*}{1333} & 3,50 & 2,50 & 6,63 & 110,50 \\
\hline & & 5,00 & 8,50 & 100,00 \\
\hline$\overline{\mathrm{m}}$ & - & - & - & 100,27 \\
\hline
\end{tabular}


TABELA 10. Teste de recuperação de ferro.

\begin{tabular}{|c|c|c|c|c|}
\hline \multirow{2}{*}{ Amostra } & \multicolumn{3}{|c|}{ Ferro $(\mu \mathrm{g})$} & \multirow{2}{*}{$\begin{array}{c}\text { Recuperação } \\
\%\end{array}$} \\
\hline & $\begin{array}{l}\text { Originalmente } \\
\text { medido }\end{array}$ & Adicionado & Encontrado & \\
\hline \multirow[t]{2}{*}{1 . } & 2,75 & 1,00 & 4,00 & 106,66 \\
\hline & & 3,60 & 6,38 & 100,47 \\
\hline \multirow[t]{2}{*}{2} & 8,88 & 5,00 & 14,25 & 102,66 \\
\hline & & 10,88 & 19,50 & 98,73 \\
\hline \multirow[t]{2}{*}{3} & 12,88 & 10,88 & 22,63 & 95,24 \\
\hline & & 32,88 & 45,25 & 98,88 \\
\hline \multirow[t]{2}{*}{37} & 0,38 & 5,00 & 5,38 & 100,00 \\
\hline & & 10,88 & 11,00 & 97,69 \\
\hline \multirow[t]{2}{*}{49} & 6,25 & 5,00 & 11,25 & 100,00 \\
\hline & & 10,88 & 17,38 & 101,45 \\
\hline$\overline{\mathrm{m}}$ & - & - & - & 100,18 \\
\hline
\end{tabular}




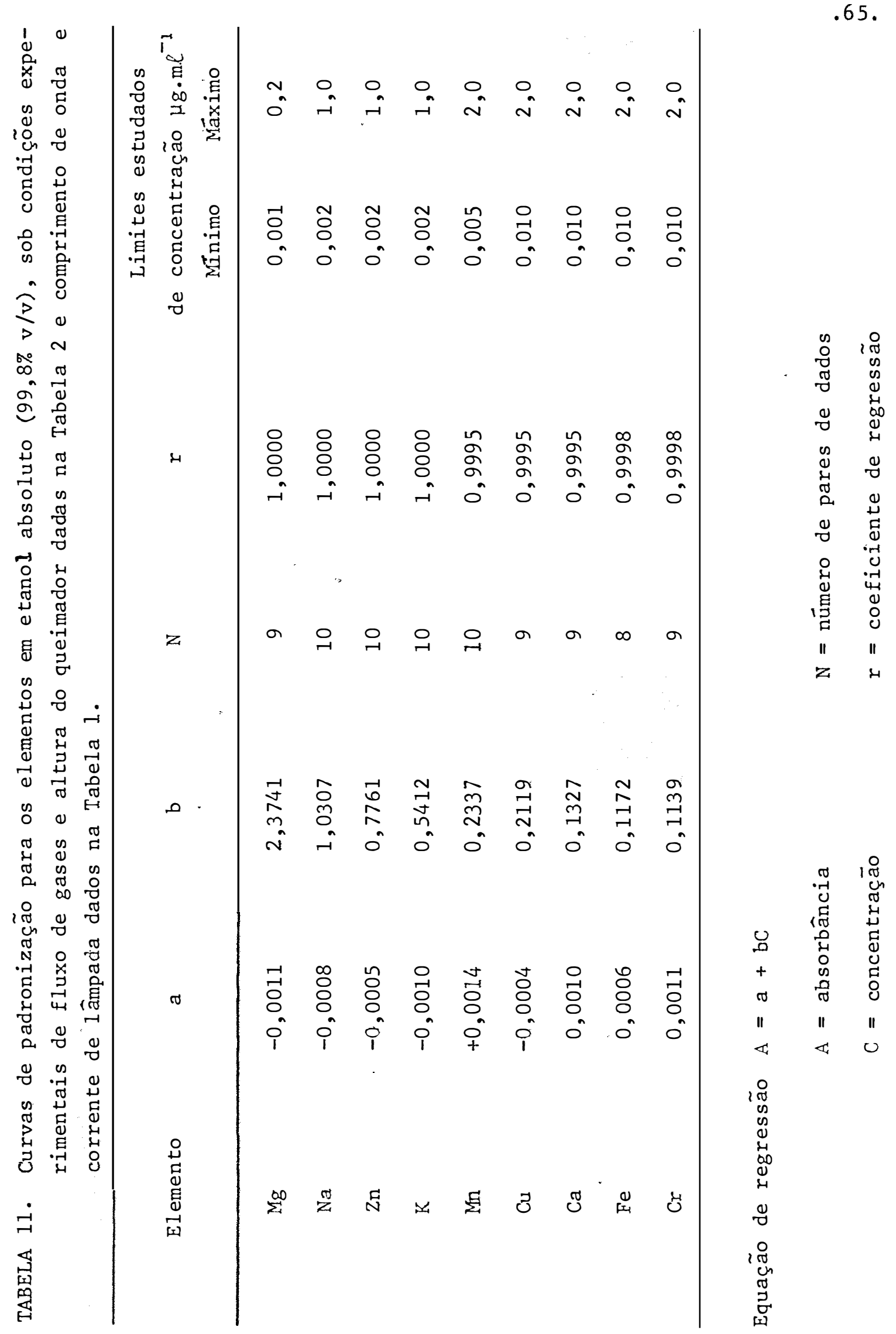




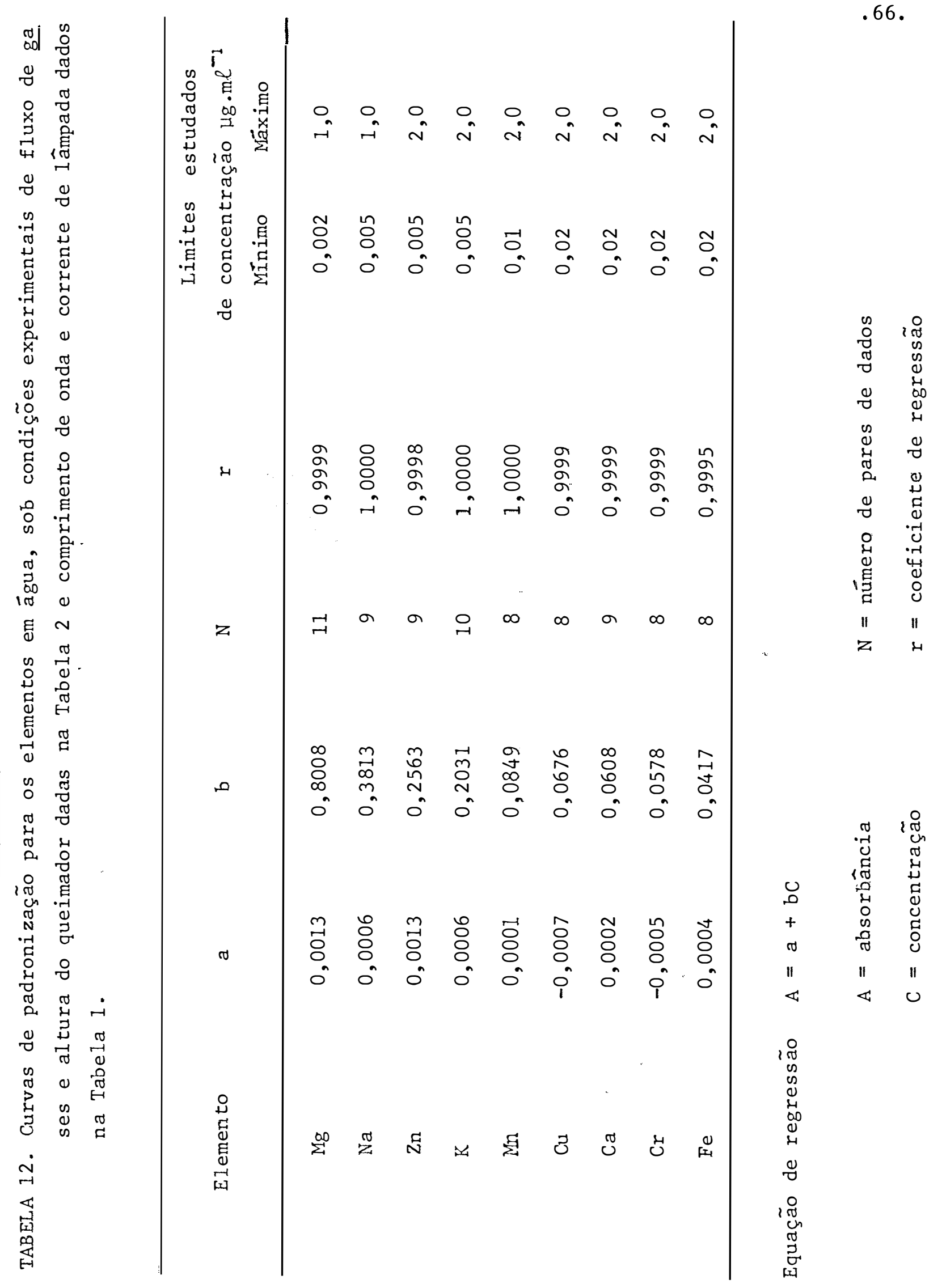


TABELA 13. Limite de deteção e sensibilidade da determinação dos elemen tos em etanol e āgua $\left(\mu g \cdot \mathrm{m} \ell^{-1}\right)$.

\begin{tabular}{ccc}
\hline Elemento & Etano1 & Água \\
\hline $\mathrm{Mg}$ & 0,0004 & 0,0013 \\
$\mathrm{Na}$ & 0,0009 & 0,0026 \\
$\mathrm{Zn}$ & 0,0013 & 0,0039 \\
$\mathrm{~K}$ & 0,0019 & 0,0049 \\
$\mathrm{Mn}$ & 0,0043 & 0,0118 \\
$\mathrm{Cu}$ & 0,0047 & 0,0148 \\
$\mathrm{Ca}$ & 0,0075 & 0,0165 \\
$\mathrm{Cr}$ & 0,0085 & 0,0173 \\
$\mathrm{Fe}$ & 0,0088 & 0,0240 \\
\hline
\end{tabular}


.68

TABELA 14. Concentrações característicæ dos elementos em etanol e ảgua.

\begin{tabular}{cccccc}
\hline & & \multicolumn{3}{c}{ Água } & \\
\cline { 3 - 6 } Elemento & Etano1 & $\begin{array}{c}\text { No presente } \\
\text { Trabalho }\end{array}$ & $\begin{array}{c}\text { THOMPSON } \\
\text { REYNOLDS } \\
(\text { I978) }\end{array}$ & WELZ (1976) & $\begin{array}{c}\text { Fator de } \\
\text { Ganho }\end{array}$ \\
\hline Mg & 0,002 & 0,006 & 0,005 & 0,01 & 3,0 \\
$\mathrm{Na}$ & 0,004 & 0,012 & 0,01 & 0,015 & 3,0 \\
$\mathrm{Zn}$ & 0,006 & 0,017 & 0,01 & 0,02 & 2,8 \\
$\mathrm{~K}$ & 0,008 & 0,022 & 0,02 & 0,05 & 2,7 \\
$\mathrm{Mn}$ & 0,019 & 0,052 & 0,03 & 0,1 & 3,1 \\
$\mathrm{Cu}$ & 0,021 & 0,065 & 0,05 & 0,1 & 2,2 \\
$\mathrm{Ca}$ & 0,033 & 0,072 & 0,05 & 0,05 & 2,8 \\
$\mathrm{Fe}$ & 0,038 & 0,106 & 0,1 & 0,2 & 2,0 \\
$\mathrm{Cr}$ & 0,039 & 0,076 & 0,08 & 0,1 & \\
\hline
\end{tabular}




\section{CONCLUSOES}

Os elementos cálcio, magnēsio, sōdio, potássio, zinco, fer ro, cobre, manganês e cromo podem ser determinados em etanol por espec trometria de absorção atômica. A anālise por aspiração direta da amos tra, sem a necessidade de qualquer preparo, apresenta as seguintes vanta gens: ocasiona um considerável ganho de tempo em anālises de rotina, re sultando em uma velocidade analítica de 120 a 150 determinações por hora; evita o risco de contaminações devido ao uso de reagentes e proporciona um baixo custo operacional.

$$
\text { Existe uma razão acetileno-ar ideal para cada elemento, }
$$
em uma determinada altura do queimador. Para os elementos cálcio, magnē sio, potássio e cromo, o fluxo dos gases è razoavelmente crítico, enquan . to que manganês, sódio e ferro apresentam pouca variação e zinco e cobre não sofrem influência dentro das razões estudadas.

O grau alcoólico das amostras exerce influência significa tiva sobre a sensibilidade das determinações. Desse modo, uma diminui ção de cínco graus alcoôlicos, a partir do etanol anidro $99,8 \% \mathrm{v} / \mathrm{v}$, re sulta em decréscimos variáveís na absorbância, de acordo com o elemento. 
Assim, verificam-se perdas aproximadas de $10 \%$ para potássio e $z$ inco, $14 \%$ para cobre, magnésio e ferro, $17 \%$ para manganês, $20 \%$ para sódio, $24 \%$ pa ra cromo e $29 \%$ para cảlcio.

As curvas de padronização devem ser preparadas em etanol anidro, devido à maior sensibilidade obtida para as graduações alcoólicas mais elevadas. As amostras com teores alcoólicos mais baixos devem ter o valor de absorbância corrigido com relação àquele encontrado na gradua ção utilizada na curva de padronização.

A faixa analítica estudada para todos os elementos está situada entre 0,001 e $2.000 \mu \mathrm{g} \cdot \mathrm{m}^{-1}$, e os coeficientes de regressão mos tram que as curvas são lineares nas concentraçöes estudadas.

As medidas de absorbância apresentam boa precisão, com des vios padrão relativos menores que $0,45 \%$ para as concentrações mais altas $\left(0,2 \mu \mathrm{g} \cdot \mathrm{m} \ell^{-1}\right.$ para magnésio, $0,5 \mu \mathrm{g} \cdot \mathrm{m} \ell^{-1}$ para zinco e sódio e $1,0 \mu \mathrm{g} \cdot \mathrm{m} \ell^{-1}$ para cobré, ferro, potássio, cromo, cálcio e manganês) e até 4,5\% para concentrações dez vezes menores.

Para os elementos presentes nas amostras em concentrações mensurāveis, médias de recuperação aproximadas de $100 \%$ foram encontradas. Desta forma, o método proposto pode ser considerado um método exato.

Os elementos podem ser determinados em etanol com os se guintes 1 imites de deteção, em $\mu g \cdot m \ell^{-1}$ : magnēsio - 0,0004; sōdio-0,0009; zinco - 0,0013; potássio - 0,0019; manganês - 0,0043; cobre - 0,0047; cả $\underline{1}$ cio - 0,0075; ferro - 0,0085 e cromo - 0,0088. 
.71.

\section{LITERATURA CITADA}

ALLAN, J.E., 1961. The use of organic solvents in atomic absorption spectrophotometry. Spectrochim. Acta, 0xford, 17:467-473.

ALMEIDA, J.R. de, 1952. Âlcool e distilaria. Piracicaba, ESALQ. $333 \mathrm{p}$.

BOWER, N.W. e J.D. INGLE Jr., 1976. Precision of flame atomic absorption measurements of copper. Anal. Chem., Washington, 48(4): 686-692.

BOWER, N.W. e J.D. INGLE Jr., 1977. Precision of flame atomic absorption measurements of arsenic, cadmium, calcium, copper, iron, magnesium, molybdenum, sodium, and zinc. Anal. Chem., Washington, 49(4): $574-579$.

BOWER, N.W. e J.D. INGLE Jr., 1979. Optimization of instrumental variables in flame atomic absorption spectrometry. Anal. Chim. Acta, Ams terdam, 105:199-212. 
BRUNING, I.M.R. de Andrade e E.B. MALM, 1980. Identificação e quantifi cação das impurezas presentes no etano?. Rio de Janeiro, Centro de Pesquisas e Desenvolvimento Leopoldo A. Miguez de Mello - CENPES,

\section{$15 \mathrm{p}$.}

CELLIER, K.M. e H.C.T. STACE, 1966. Determination of optimum operating conditions in atomic absorption spectroscopy. Appl. Spectrosc.,

Bound Brook, 20(1):26-33.

CHAKRABARII; C.L. e S.P. SINGHAL, 1969. Effect of complexing agents and organic solvents on the sensitivity of atomic-absorption spectro scopy technique. Spectrochim. Acta, Oxford, 24B(12) 663-677.

CHRISTIAN, G.D. e F.J. FELDMAN, 1970. Atomic absorption spectroscopy: Applications in Agriculture, Biology and Medicine. New York, WileyInterscience. $490 \mathrm{p}$.

- DAGNALL, R.M. e T.S. WEST, 1964. Observations on the atomic absorption spectroscopy of lead in aqueous solution, in organic extracts and in gasoline. Talanta, London, 11:1553-1557.

ELWELL, W.T. e J.A.F. GIDLEY, 1962. Atomic absorption spectrophotometry. New York, MacMillan. 102 p.

FELDMAN, F.J., R.E. BOSSHART e G.D. CHRISTIAN, 1967. Sensitivity of manganese determination by atomic absorption spectrometry using four solvents. Anal. Chem., Washington, $39(10): 1175-1177$.

FELDMAN, F.J. e W.C. PURDY, 1965. The atomic absorption spectroscopy of chromium. Anal. Chim. Acta, Amsterdam, 33:273-278. 
GEGIOU, D. e M. BOTSIVALI, 1975. Atomic absorption spectrophotometric determination of lead in beverages and fruit juices and of lead extracted by their action on glazed ceramic surfaces. Analyst, London, 900:234-237.

GIBSON, J.H., W.E.L. GROSSMAN e W.D. COOKE, 1963. Excitation process

in flame spectrometry. Ana1. Chem., Washington, 35(3):266-277.

GOUX, R., 1975. Petroleum products. In: PINTA, M. Atomic absorption. spectrometry. Translated by K.M. Greenland and F. Lawson. London, Adam Hilger. p. 290.

HARRISON, W.W. e P.O. JULIANO, 1969. Effects of organic solvents on tin absorbance in an air-hydrogen flame. Anal. Chem., Washington, $\underline{41}(8): 1016-1021$.

HOFFMAN, C.M., R.L. BRUNELLE', M.J. PRO e G.E. MARTIN, 1968. Determina tion of trace component distribution in illicit spirits by neutron activation analysis (NAA), atomic absorption (AA), and gas-1iquid chromatography (GLC). J. Assoc. Off. Anal. Chem., Washington,

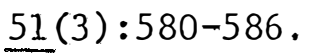

INGLE Jr., J.D., 1974. Precision of atomic absorption spectrometric measurements. Ana1. Chem., Washington, 46(14):2161-2171.

INTERNATIONAL UNION OF PURE AND APPLIED CHEMTSTRY. Commission on spectrochemical and other optical procedures for analysis, 1978. Nomenclature, symbols, units and their usage in spectrochemical analysis I, II, III. Spectrochim. Acta, Oxford, 33B(6):220-278. 
LEMONDS, A.J. e B.E. MCCLELLAN, 1973. Correlation of enhancement of atomic absorption sensitivity for selected metal ions with physical properties of organic solvents. Anal. Chem., Washington, 45(8): $1455-1460$.

LOCKYER, R., eT.E. SCOTT e S. SLADE, 1961. Enhancement of atomic absorption in the flame by organic solvents. Nature, Hants, 189(11): $830-831$

MERANGER, J.C. e E. SOMERS, 1968. Determination of heavy metals in wines by atomic absorption spectrophotometry. J. Assoc. Off. Anal. Chem., Washington, 51(4):922-925.

MEREDITH, M.K., S. BALDWIN e A.A. ANDREASEN, 1970. Determination of iron in alcoholic beverages. J.Assoc. Off. Anal. Chem., Washington,

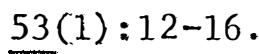

MONICK, J.A., 1968. Alcohols: their chemistry properties and manufacture. New York, Reinhold Book. 594 p.

PALACIO LLAMES, H., 1956. Fabricacion del alcohol. Barcelona, Salvat Editores. $735 \mathrm{p}$.

PANDAY, V.K. e A.K. GANGULY, 1970. The use of water-miscible organic solvents in atomic absorption spectrophotometry. Anal. Chim. Acta, Amsterdam, 52:417-423.

PERKIN-ELMER, 1974. Model 306: Atomic absorption spectrophotometer. Norwalk. 
PINTA, M., 1975. Determination of optimal analytical conditions. In: - Atomic absorption spectrometry. Translated by K.M.

Greenland and F. Sawson. London, Adam Hilger, p. 120-142.

POPHAM, R.E. e W.G. SCHRENK, 1968. Atomic absorption characteristics of germanium. Spectrochim. Acta, Oxford, 23B (8):543-551.

RAMIREZ-MUÑNOZ, J., 1968. Atomic-absorption spectroscopy and analysis by atomic-absorption flame photometry. Amsterdam, Elsevier, 493 p.

RANN, C.S. e A.N. HAMBLY, 1965. Distribution of atoms in an atomic absorption flame. Anal. Chem., Washington, 37(7):879-884.

RIANDEY, C., 1975. Interference. In: PINTA, M. Atomic absorption. spectrometry. Translated by K.M. Greenland and F. Lawson. London, Adam Hilger. p. 74 .

ROBINSON, J.W., 1960. Effect of organic and aqueous solvents on flame photometric emission and atomic absorption spectroscopy. Anal. Chim. Acta, Amsterdam, $23: 479-487$.

ROBINSON, J.W. e L.J. KEVAN, 1963. Further observations in atomic absorption spectroscopy. Anal. Chim. Acta, Amsterdam, 28:170-175.

SACHDEV, S.L., J.W. ROBINSON e P.W. WEST, 1967. Effect of mixed organic solvents on atomic absorption spectrophotometry of refractory metals. Anal. Chim. Acta, Amsterdam, 37:156-163. 
SCHALLIS, J.E. eH.L. KAHN, 1968. The place of the air-hydrogen flame in atomic absorption spectrophotometry. Atom. Absorpt. Newsl., Norwalk, $\underline{7}(4): 75$.

SLAVIN, W., 1965. Applications of atomic absorption spectroscopy in the food industry. Atom. Absorpt. News1., Norwa1k, 4(8):330-333.

SLAVIN, W., S. SPRAGUE e D.C. MANNING, 1963. The determination of calcium by atomic absorption spectrophotometry. Atom. Absorpt. Newsl. Norwalk, $15: 1.8$.

STRUNK, D.H. e A.A. ANDREASEN, 1967. Collaborative study using atomic absorption spectrophotometry for the determination of copper in alcoholic products. J.Assoc. Off. Anal. Chem., Washington, 50 (2): 338-339.

STUPIELLO, J.P., W. BALBO e E.A. MARINO, (1973). Destilação. Piracica ba, COPERSUCAR. $131 \mathrm{p}$.

SLIVOS, K., L. POLOS e E. PUNGOR, 1976. The effect of nebulizer parameters on the enhancement of flame spectrometric sensitivity by organic solvents. Spectrochim. Acta, Oxford, 31B(5):289-294.

THOMPSON, K.C. e R.J. REYNOLDS, 1978. Atomic absorption fluorescence. and flame emission spectroscopy: A pratical approach. 2. ed., London, Charles Griffin, 319 p.

VARJU, M.E., 1972. The determination of copper, iron, and magnesium in alcoholic products using atomic absorption spectroscopy. Atom. Absorp. News1., Norwalk, $11(2): 45$. 
WEL2, B., 1976. Atomic absorption spectroscopy. Translated by C. Skegg. New York, Verlag Chimie, 267 p.

WINEFORDNER, J.D., C.T. MANSFIELD e T.J. VICKERS, 1963. Atomization efficiency of total consumption atomizer-burners in flame photometry. Ana1. Chem., Washington, 35(11):1607-1610.

ZEEMAN, P.B. e L.R.P. BUTLER, 1962. The determination of lead, copper and zinc in wines by atomic absorption spectroscopy. App1. Spectrosc., Bound Brook, 16:120-124. 